\title{
A Conceptual Design for a Desktop Application to Support Inventory Reconciliation Activities
}

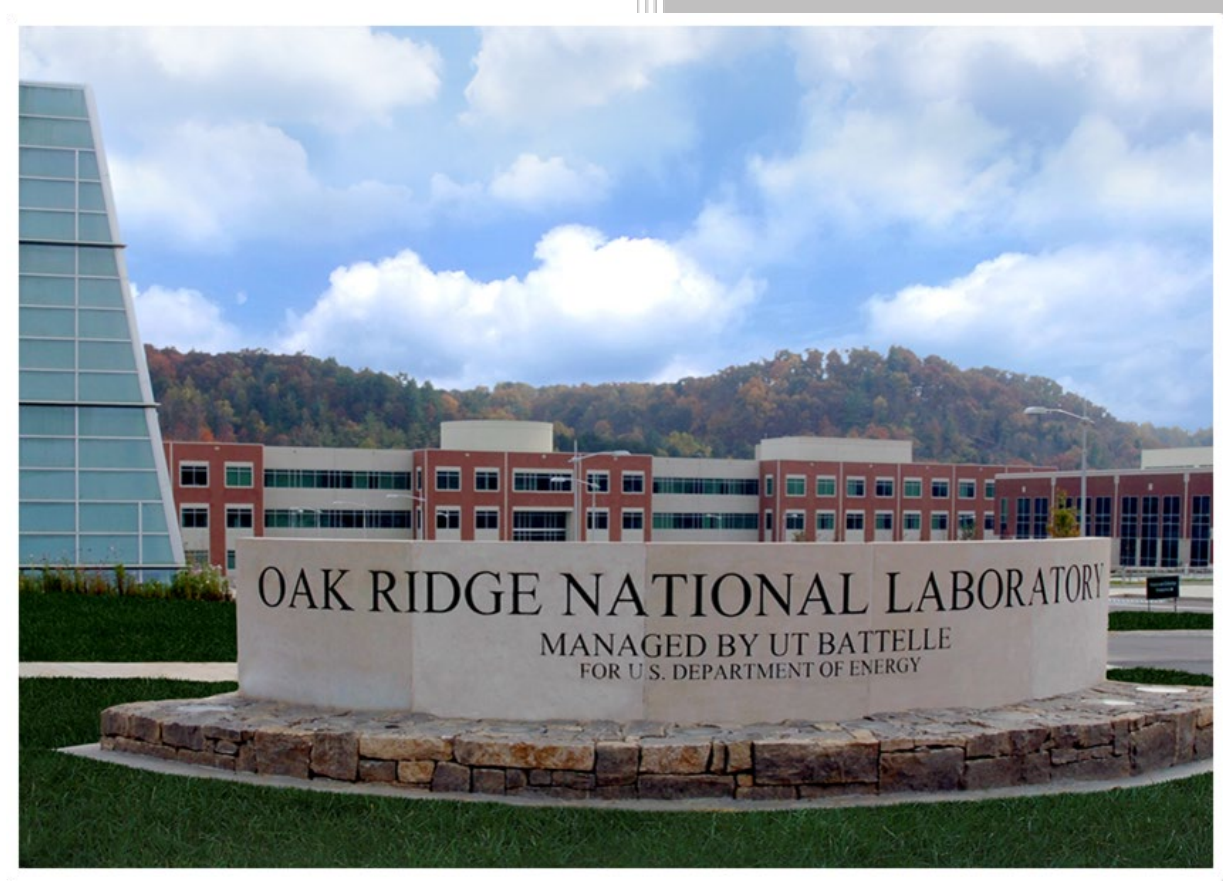

Natalie McGirl Jim Garner

December 2020 


\section{DOCUMENT AVAILABILITY}

Reports produced after January 1, 1996, are generally available free via US Department of Energy (DOE) SciTech Connect.

Website www.osti.gov

Reports produced before January 1, 1996, may be purchased by members of the public from the following source:

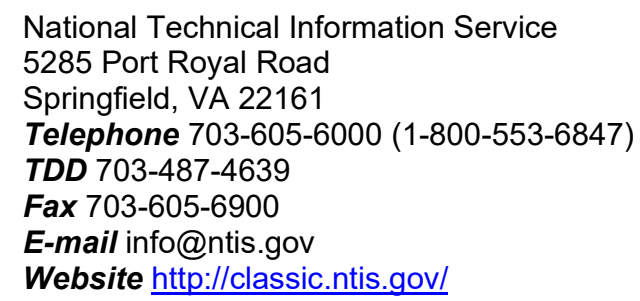

Reports are available to DOE employees, DOE contractors, Energy Technology Data Exchange representatives, and International Nuclear Information System representatives from the following source:

Office of Scientific and Technical Information

PO Box 62

Oak Ridge, TN 37831

Telephone 865-576-8401

Fax 865-576-5728

E-mail reports@osti.gov

Website http://www.osti.gov/contact.html

This report was prepared as an account of work sponsored by an agency of the United States Government. Neither the United States Government nor any agency thereof, nor any of their employees, makes any warranty, express or implied, or assumes any legal liability or responsibility for the accuracy, completeness, or usefulness of any information, apparatus, product, or process disclosed, or represents that its use would not infringe privately owned rights. Reference herein to any specific commercial product, process, or service by trade name, trademark, manufacturer, or otherwise, does not necessarily constitute or imply its endorsement, recommendation, or favoring by the United States Government or any agency thereof. The views and opinions of authors expressed herein do not necessarily state or reflect those of the United States Government or any agency thereof. 
Nuclear Nonproliferation Division

\title{
A CONCEPTUAL DESIGN FOR A DESKTOP APPLICATION TO SUPPORT INVENTORY RECONCILIATION ACTIVITIES
}

\author{
Natalie McGirl \\ Jim Garner
}

Date Published: December 2020

Prepared by

OAK RIDGE NATIONAL LABORATORY

Oak Ridge, TN 37831-6283

managed by

UT-BATTELLE, LLC

for the

US DEPARTMENT OF ENERGY

under contract DE-AC05-00OR22725 



\section{CONTENTS}

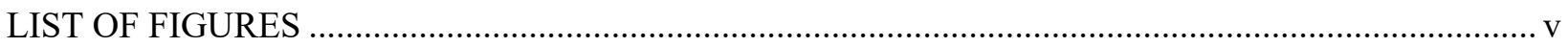

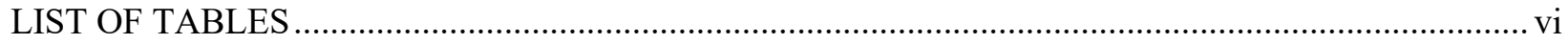

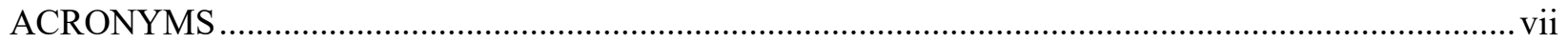

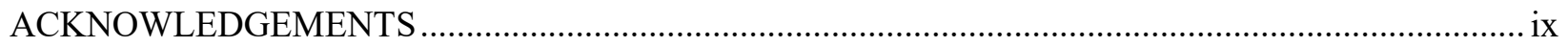

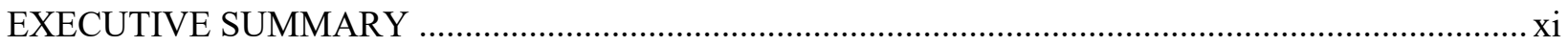

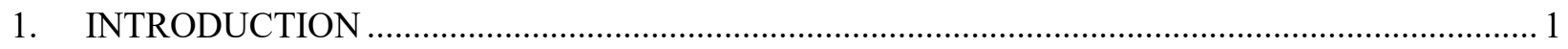

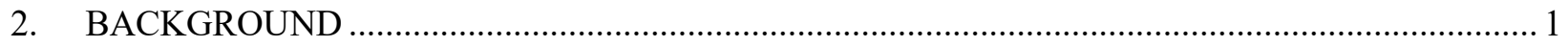

3. EXAMPLE USE CASE: IAEA ITEM COUNTING AND TAG CHECKING ACTIVITIES

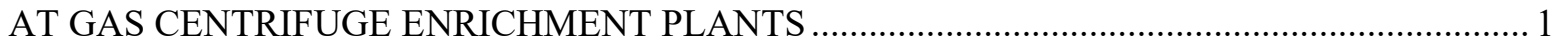

4. CONCEPTUAL WORKFLOW FOR INVENTORY ASSISTANT …............................................ 3

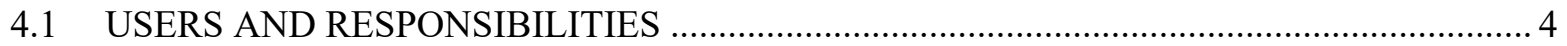

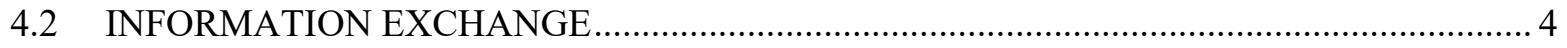

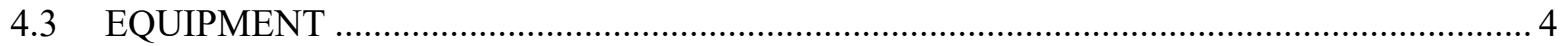

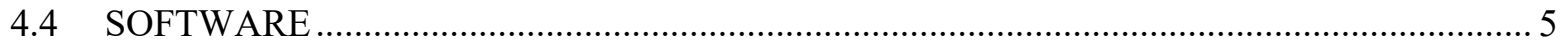

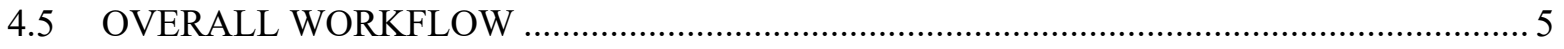

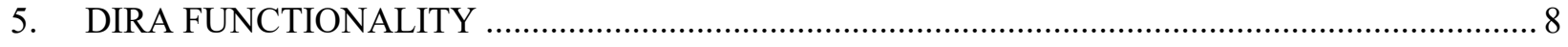

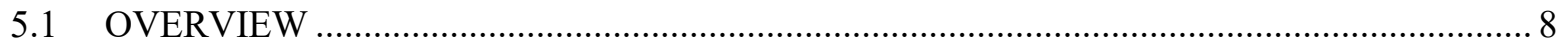

5.2 INTRODUCTION TO REPRESENTATIVE SCENARIOS ............................................. 9

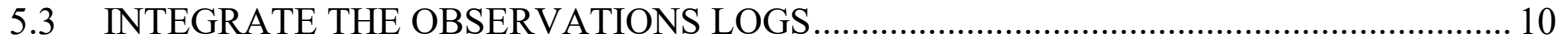

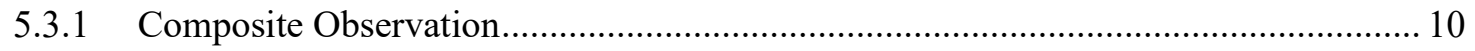

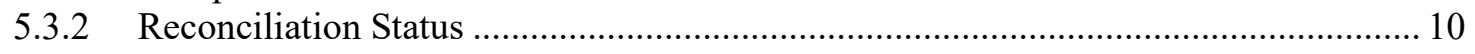

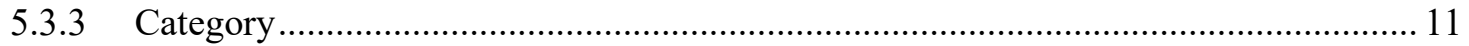

5.4 POTENTIAL IN-FIELD SCENARIOS WITH COMPOSITE OBSERVATION,

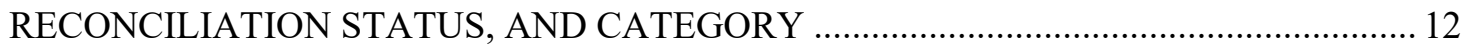

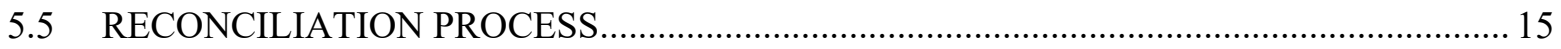

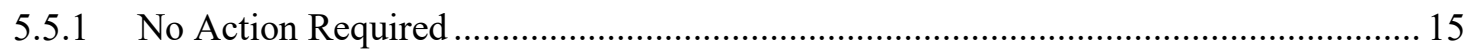

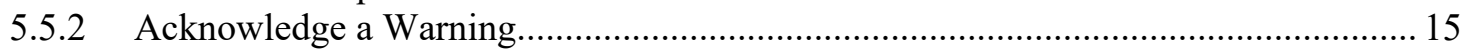

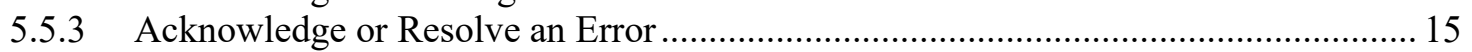

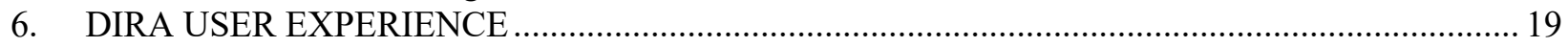

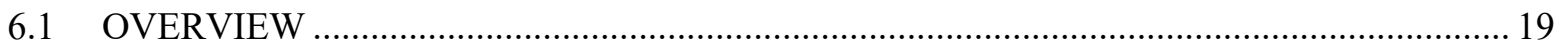

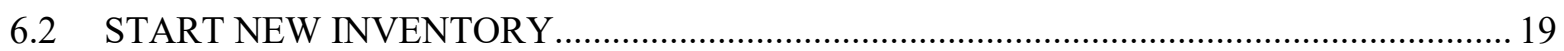

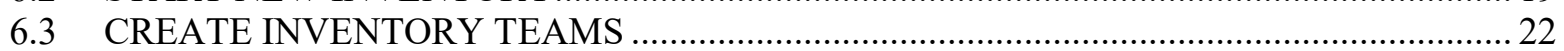

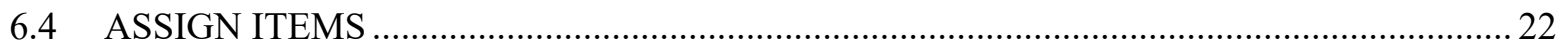

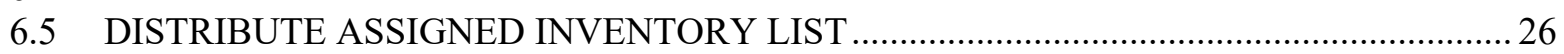

6.6 FIELD OBSERVATION ACTIVITIES IN PROGRESS ............................................ 27

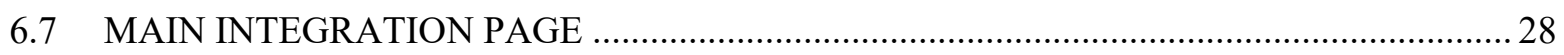

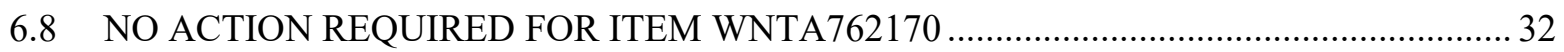

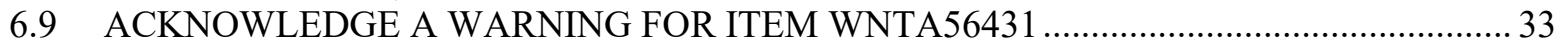

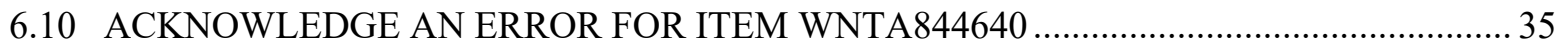

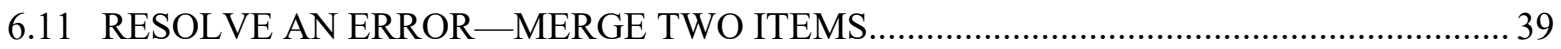

6.12 RESOLVE AN ERROR-ASSOCIATE AN OBSERVATION TO CORRECT ITEM ......... 44

6.13 GENERATE SUMMARY REPORT AND FINALIZE INVENTORY …........................... 48

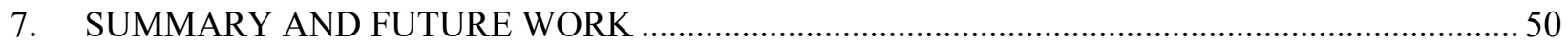

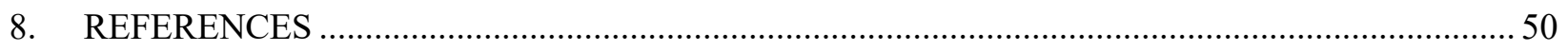





\section{LIST OF FIGURES}

Figure 1. Multiple inventory teams are typically deployed to conduct item counting and tag checking activities using a paper-based inventory listing like the one shown in the

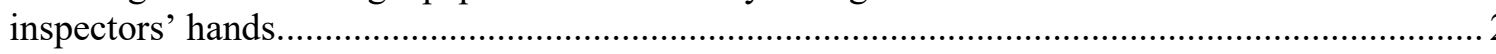

Figure 2. Finding all of the items listed on paper-based inventory listings can be time-consuming and confusing, as illustrated by the two inspectors searching a large storage room for a

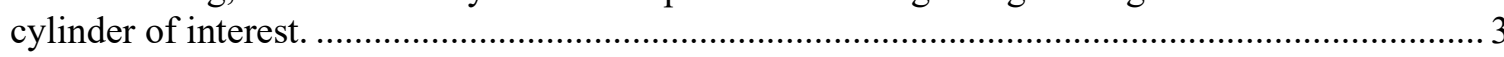

Figure 3. Information exchange key for inventory assistant workflow. ........................................ 6

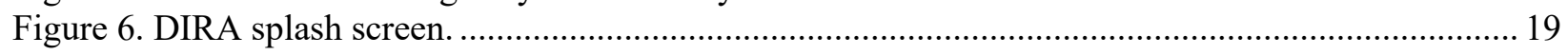

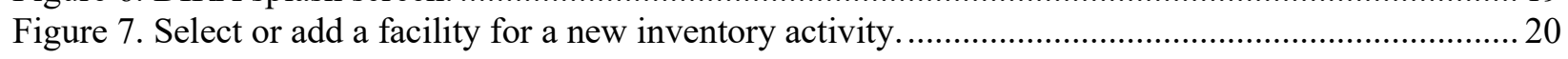

Figure 8. Browse files to upload the operator-provided inventory list. ................................................2 20

Figure 9. Select facility and time period to view the summary report for a completed inventory

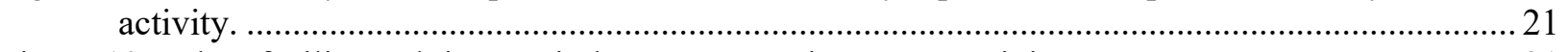

Figure 10. Select facility and time period to resume an inventory activity. .......................................2

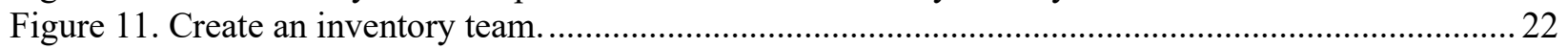

Figure 12. Assign a percentage of the inventory list to each team. ....................................................2 23

Figure 13. Inventory assignment, all rows collapsed......................................................................2 24

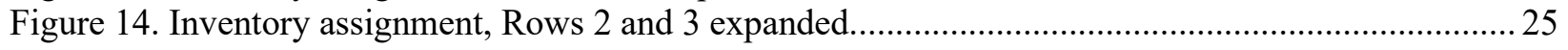

Figure 15. Upload assigned inventory list to each team's mobile device .............................................26

Figure 16. In-field observation activities in progress..................................................................... 27

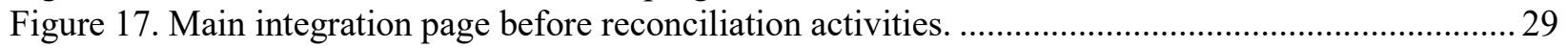

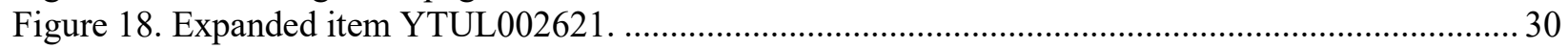

Figure 19. Displayed comment for item YTUL002621................................................................ 31

Figure 20. Items like WNTA762170 require no action from the inventory lead................................... 32

Figure 21. Item WNTA56431 has a warning reconciliation status and needs action by the

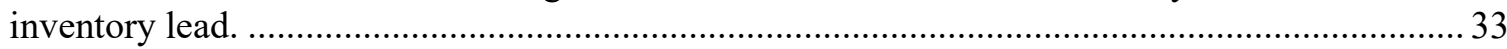

Figure 22. The warning for item WNTA56431 is acknowledged by the inventory lead. Composite observation does not change, and the reconciliation status is grayed out..................................... 34

Figure 23. Item WNTA844640 (Not Observed) has an error reconciliation status and needs action

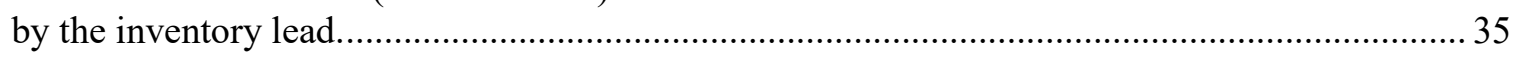

Figure 24. Initial reconciliation page for item WNTA844640 (Not Observed)........................................ 36

Figure 25. Reconciliation page for item WNTA844640 (Not Observed) after inventory lead adds

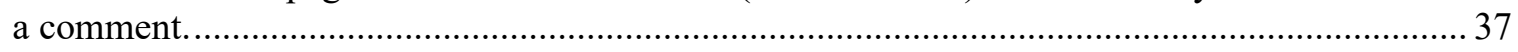

Figure 26. Item WNTA844640 (Not Observed) after the inventory lead acknowledges the error. Composite observation does not change, and the reconciliation status is grayed out................... 38

Figure 27. Items WNTA762169 (Not Observed) and WNTA762196 (Added to List) have an error reconciliation status and need action by the inventory lead........................................................ 39

Figure 28. Initial reconciliation page for item WNTA762169 (Not Observed)..................................... 40

Figure 29. Reconciliation page for item WNTA762169 (Not Observed) after inventory lead selects item WNTA762196 (Added to List) to merge.

Figure 30. Reconciliation page for item WNTA762169 (Not Observed) after inventory lead adds

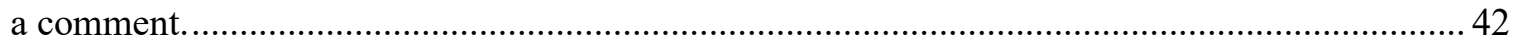

Figure 31. Merged item WNTA762169 after the inventory lead resolves the error............................... 43

Figure 32. Items YTUL002621 (Duplicate - Within Team) and KYTL15095 (Not Observed) have an error reconciliation status and need action by the inventory lead................................... 44

Figure 33. Initial reconciliation page for item YTUL002621 (Duplicate - Within Team)....................... 45

Figure 34. Reconciliation page for item YTUL002621 (Duplicate - Within Team) after inventory lead selects item KYTL150695 (Not Observed) to merge. 
Figure 35. Reconciliation page for item YTUL002621 (Duplicate - Within Team) after inventory lead adds a comment.

Figure 36. Items YTUL002621 and KYTL150695 after the inventory lead resolves the errors.

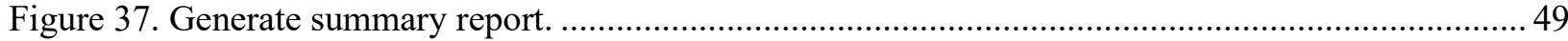

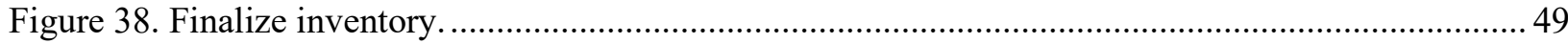

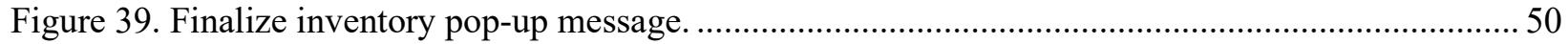

\section{LIST OF TABLES}

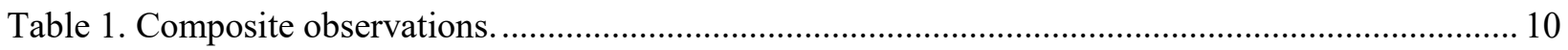

Table 2. Reconciliation status with associated inventory lead action................................................. 11

Table 3. DIRA-assigned reconciliation status and required inventory lead actions for each composite observation.

Table 4. Potential in-field scenarios, associated actions by the inventory team, and DIRAassigned composite observations and reconciliation status.

Table 5. No action required.

Table 6. Process to acknowledge a warning.

Table 7. Process to acknowledge an error

Table 8. Process to resolve an error. 


\section{ACRONYMS}

DIRA Distribution, Integration, and Reconciliation Application

GCEP gas centrifuge enrichment plant

IFOA In-Field Observations App

ORNL Oak Ridge National Laboratory 



\section{ACKNOWLEDGEMENTS}

The authors would like to thank Megan Gaylor and Joyanna Hirst at Cadre5 for their user experience design work presented throughout this report. The authors would also like to thank Michael Whitaker (Oak Ridge National Laboratory), Tommy Adkins (Oak Ridge National Laboratory), and Ed Wonder (Ayr Hill Group LLC, a subcontractor to Brookhaven National Laboratory) for their technical reviews and helpful comments. 



\section{EXECUTIVE SUMMARY}

This paper describes desktop software being developed at Oak Ridge National Laboratory (ORNL) to empower users to reconcile observations about items at nuclear facilities more accurately, reliably, and quickly. Inventory activities at nuclear facilities are often conducted using pen and paper, which can be time-consuming, tedious, and susceptible to reading or transcription errors. The proposed inventory assistant would be a replacement for the paper-based process that could be used by International Atomic Energy Agency (IAEA) inspectors, nuclear facility operators, or treaty verification monitors to conduct an inventory of nuclear and non-nuclear items in a more timely and accurate manner. Garner, McGirl, and Whitaker previously reported their work about a conceptual design for a mobile app to assist users in the field [1].

In general, the inventory assistant would ingest an inventory list, distribute assigned items from the inventory list to one or more mobile devices, enable inventory teams to record their observations in the field, and then enable an inventory lead to integrate and reconcile the observations to produce a final report. The assistant consists of two software components - one for the inventory teams to record observations in the field (In-Field Observations App [IFOA]) and one for the inventory lead to (1) distribute the inventory list to each team, (2) integrate the observations from each team, and (3) reconcile the inventory list with observations (Distribution, Integration, and Reconciliation Application [DIRA]). This paper reviews the inventory assistant workflow and describes the DIRA user experience in more detail.

As an example, the authors have chosen to follow the use case of IAEA inspectors conducting item counting and tag checking activities of $\mathrm{UF}_{6}$ cylinders at a gas centrifuge enrichment plant with a large number of $\mathrm{UF}_{6}$ cylinders (e.g., thousands). These activities can currently require 30-40 person-days of inspection to complete. The authors believe an inventory assistant could allow the IAEA to complete item counting and tag checking using the global identifier or the operator's barcode in 8-10 person-days of inspection. ${ }^{1}$ We would expect other users (e.g., facility operators or treaty verification monitors) to also benefit from significant time savings.

\footnotetext{
${ }^{1}$ Based on exercises performed at the IAEA by the ORNL team in 2016, a user familiar with the software and the exercise could complete an inventory of 50 cylinders in approximately 40 minutes using a pen and paper method, 30 minutes when assisted with software on a tablet, and about 10 minutes when most cylinders included a barcode.
} 


\section{INTRODUCTION}

To enable International Atomic Energy Agency (IAEA) inspectors to accurately reconcile observations about items at nuclear facilities, Oak Ridge National Laboratory (ORNL) has developed an inventory assistant concept consisting of two software components - the In-Field Observations App (IFOA) and the Distribution, Integration, and Reconciliation Application (DIRA). IFOA was introduced in this report's sister publication, A Conceptual Design for a Mobile Application to Support Infield Inventory Activities (ORNL/TM-2020/1646). This report reviews the inventory assistant workflow and describes the DIRA user experience in more detail, using IAEA inspectors conducting item counting and tag checking activities of $\mathrm{UF}_{6}$ cylinders at a gas centrifuge enrichment plant with a large number of $\mathrm{UF}_{6}$ cylinders as a case study. Sections 2-4 are reproduced from ORNL/TM-2020/1646 to provide context for the later discussions. Sections 5-6 explore the tool's functionality and user experience.

\section{BACKGROUND}

As discussed in [1], many industries uniquely identify individual items and inventory them on a regular basis. However, commercial off-the-shelf inventory software typically requires the items to be barcoded, which is not always the case at nuclear facilities. For example, $\mathrm{UF}_{6}$ cylinders are commonly found at conversion, enrichment, and fuel fabrication facilities and can have a service life of 40 years or longer [2], [3]. Although some operators affix a vinyl label with their own identification number and a onedimensional (1D) barcode, some cylinders produced in the last few years may include a larger laseretched global identification number and a two-dimensional (2D) barcode; the ANSI and ISO specifications only require cylinders to have a debossed (stamped) serial number on the stainless steel nameplate. To accurately and quickly perform inventory activities for a wide variety of items at nuclear facilities, an inventory assistant should be able to efficiently inventory items with only a serial number as well as those with 1D or 2D barcodes.

The use case for IAEA inspection activities at gas centrifuge enrichment plants is explored in detail in Section 2, but the proposed inventory assistant may also be valuable to other users at nuclear facilities. For example, nuclear facility operators may be interested in using this tool to inventory nuclear items or other equipment that may or may not have an affixed barcode, as well items that may have more than one identification number. For verification monitors, an inventory assistant may be used to inventory equipment or items (e.g., B-25 boxes, drums, cylinders, etc.), or to create inventory listings for previously unreported items at fuel cycle facilities. Furthermore, the proposed inventory assistant can accommodate two or more identification numbers, providing sufficient flexibility to accommodate local operator practices.

In all scenarios, use of this inventory assistant would ease the creation and maintenance of more accurate and complete inventory listings for items with and without affixed barcodes, as well as items with multiple identification numbers.

\section{EXAMPLE USE CASE: IAEA ITEM COUNTING AND TAG CHECKING ACTIVITIES AT GAS CENTRIFUGE ENRICHMENT PLANTS}

A large commercial gas centrifuge enrichment plant may have thousands of $\mathrm{UF}_{6}$ cylinders on-site. Its annual physical inventory verification could take 2-4 weeks for four to six teams of inspectors to complete item counting and tag checking activities on those cylinders. This can require up to 30-40 IAEA 
person-days of inspection ${ }^{2}$ with a similar burden on Euratom and proportional burden on the facility operator.

Currently IAEA item counting and tag checking activities are paper-based and do not leverage the value of existing barcodes on $\mathrm{UF}_{6}$ cylinders. The facility operator may provide the IAEA inventory lead with a paper or electronic inventory list. The inventory lead then distributes the list to their teams of inspectors. Often each team will consist of an IAEA inspector, a Euratom inspector, and a facility escort. As shown in Figure 1, each team is asked to match the identification number on its assigned portion of the paper inventory list to a debossed (stamped) serial number on the stainless steel nameplate or to the operator's identification number printed on a vinyl label [4]. This process is time-intensive, requiring the inventory teams to laboriously find and read the identification number as marked on the cylinder, find the corresponding identification number on the paper list, and then manually mark it off. ${ }^{3}$ As a result, this process is potentially prone to reading or character transposition errors. When a $\mathrm{UF}_{6}$ cylinder cannot be found in its listed location, the inspectors may need to extensively search the facility, which may contain thousands of cylinders (Figure 2).

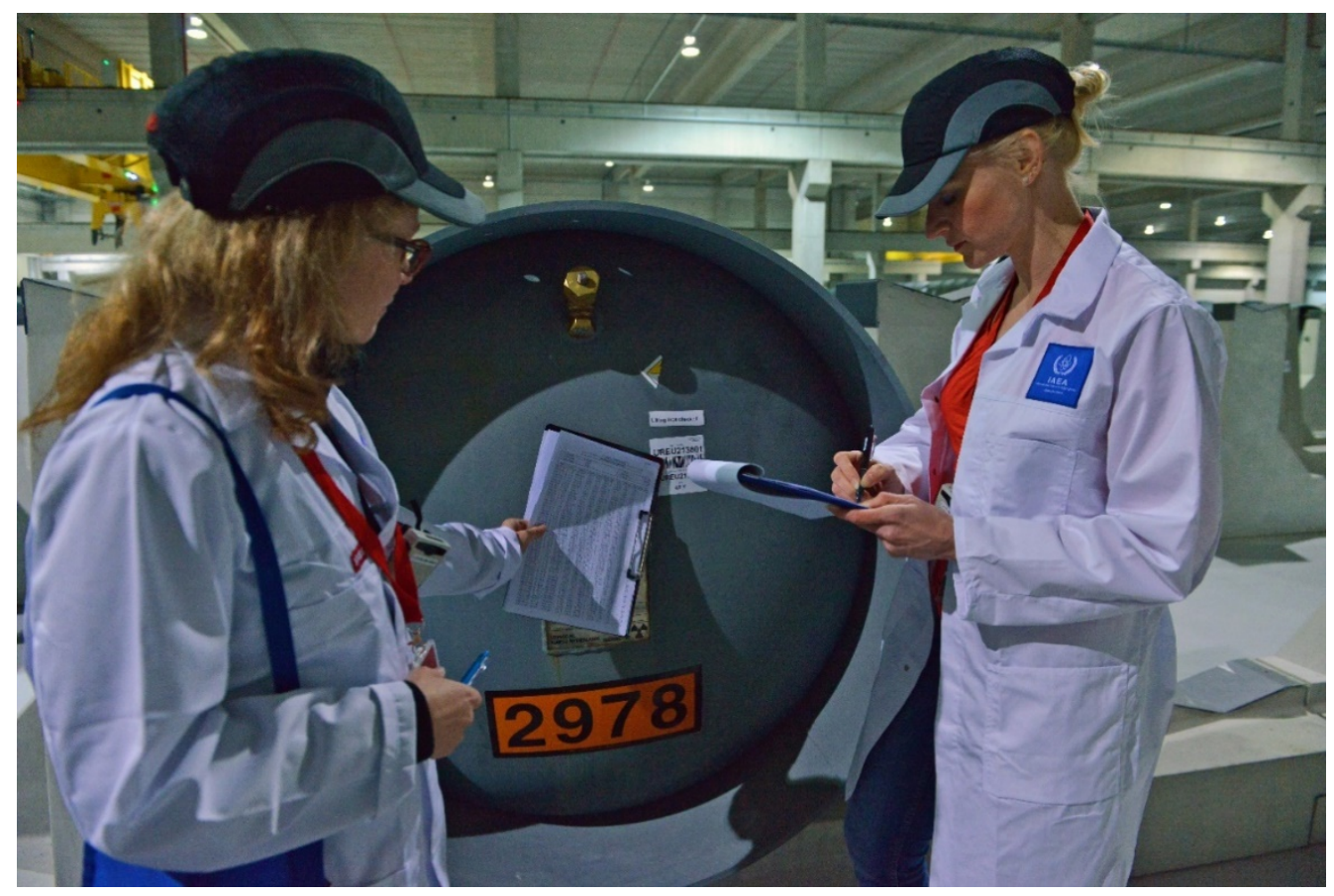

Figure 1. Multiple inventory teams are typically deployed to conduct item counting and tag checking activities using a paper-based inventory listing like the one shown in the inspectors' hands. ${ }^{4}$

\footnotetext{
${ }^{2}$ According to the IAEA, a person-day of inspection is a day during which a single inspector has access to a facility at any time for a total of no more than 8 hours [5].

${ }^{3}$ The following link shows typical activities that occur during an IAEA inspection at a nuclear fuel cycle facility: https://www.youtube.com/watch?v=Pf1MtMxnEEc

${ }^{4}$ Reprinted from https://www.flickr.com/photos/iaea_imagebank/22166534096/in/album-72157659464420989/. Some rights reserved. Distributed under the terms of the Creative Commons Attribution-NonCommercial-NoDerivs 2.0 Generic [CC BY-NCND 2.0] license.
} 


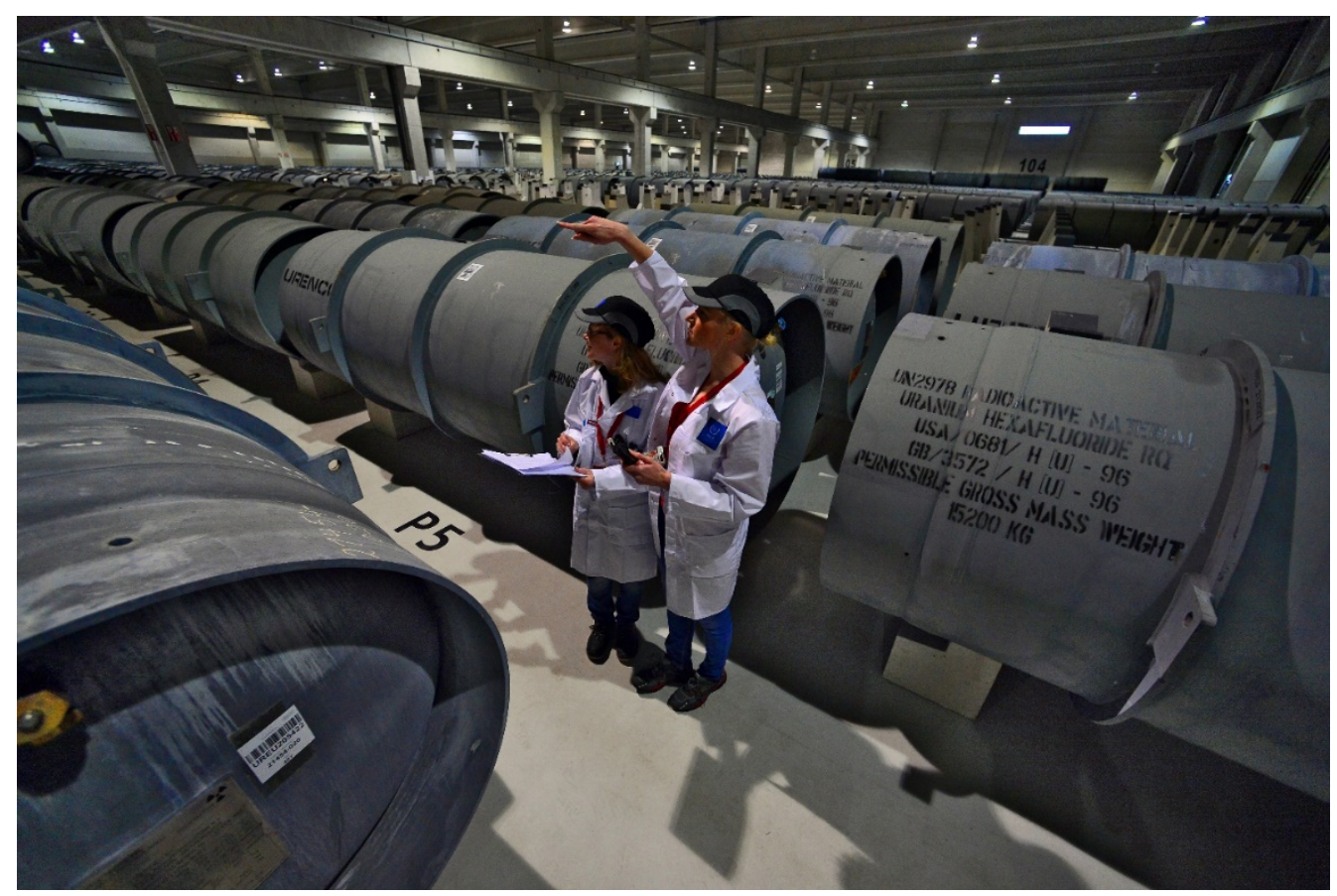

Figure 2. Finding all of the items listed on paper-based inventory listings can be time-consuming and confusing, as illustrated by the two inspectors searching a large storage room for a cylinder of interest. ${ }^{5}$

Once the inventory teams have attempted to find the items on their portion of the inventory list, the inventory lead then must collect and merge the hand-written forms and manually identify and tabulate any differences. Irregularities are common, including cylinders on the inventory list that were not observed in the field, cylinders observed in the field that are not on the inventory list, or separate teams that report observing the same cylinder [4]. The inventory lead must then reconcile these irregularities with the operator before producing a final report.

\section{CONCEPTUAL WORKFLOW FOR INVENTORY ASSISTANT}

The ORNL team envisions that the inventory assistant would have a component for activities conducted in an office at the facility as well as a component that would be used in the field at the facility (cylinder yard, feed and withdrawal area, etc.). The authors named the software used in the office the Distribution, Integration, and Reconciliation Application (DIRA) and the companion software used in the field the InField Observations App (IFOA).

In the on-site office, DIRA could be used on a desktop or laptop computer to ingest the inventory list and distribute the assigned items to the inventory teams. In the field, each inventory team would use the IFOA loaded on a mobile device to make observations about the items on their portion of the inventory list or about other items that they observe. Once the inventory teams completed their portion of the inventory list, the inventory lead would use DIRA on a desktop or laptop computer to integrate the observations from each team, then reconcile any irregularities between the operator-provided inventory list and the recorded observations before producing the final inventory report.

\footnotetext{
5 Reprinted from https://www.flickr.com/photos/iaea_imagebank/22192664675/in/album-72157659464420989/. Some rights reserved. Distributed under the terms of the Creative Commons Attribution-NonCommercial-NoDerivs 2.0 Generic [CC BY-NCND 2.0] license.
} 
The inventory assistant workflow was introduced in [1] and is reported below in Sections 4.1-4.5.

\subsection{USERS AND RESPONSIBILITIES}

The inventory assistant is being designed to help the following users:

1. Facility Operator: The point of contact at a given facility who is responsible for providing the inventory list to the inventory lead.

2. Inventory Lead (lead): The lead is responsible for determining the number of inventory teams and assigning portions of the operator-provided inventory list to each team. The number of teams per facility is typically dependent upon the number of items on the list, size of the facility, and number of persons available for the activity. Once the field observations are complete, the lead will download and combine the observations logs produced by the inventory teams, identify any irregularities from the inventory list, and reconcile with the facility operator. Once the irregularities are addressed, the lead generates a final summary report.

3. Inventory Team (team): Each inventory team consisting of one or more persons reports to the inventory lead. Each team is responsible for downloading their assigned inventory list onto their mobile device, entering the item storage location, recording their observations, and synchronizing observations $\log$ s to the office computer.

\subsection{INFORMATION EXCHANGE}

The inventory assistant will exchange the following types of information between its components:

1. Inventory List: Operator-provided list of items to be observed (e.g., XML, CSV, JSON, or another file type).

2. Assigned Inventory List: The inventory list with portions assigned by the inventory lead to specific inventory teams. Although the full inventory list will be transmitted to all teams, each team is only prompted to record their observations on their assigned portion.

3. Observations Log: The log of observations recorded by each inventory team. The observations log would be time-stamped and attributable to specific teams. The observations log contains information on the status of the assigned inventory list with comments, as well new entries for observed items not on the provided inventory list and observed items with duplicate identification numbers.

4. Summary Report: The inventory lead generates a summary report that contains the status of recorded observations for all listed items and all additional items observed that were not on the operatorprovided inventory list.

\subsection{EQUIPMENT}

The inventory assistant will consist of the following hardware components:

1. Operator Computer: An operator-controlled laptop or desktop computer used to provide the inventory list to the inventory lead.

2. Office Computer: A Windows 10 laptop or desktop computer that contains the datastore and runs DIRA. It interfaces with the operator's computer and the mobile device(s). 
3. Mobile Device: An Android smartphone, an iOS smartphone, or a Windows 10 tablet that interfaces with the office computer and runs the IFOA. One device is distributed to each inventory team.

4. Mobile Device Dock: A docking station that connects each mobile device to the office computer.

\subsection{SOFTWARE}

The inventory assistant will consist of the following software components:

1. Distribution, Integration, and Reconciliation Application (DIRA): This application is installed on the office computer. The inventory lead uses it to
a. exchange information with the datastore,
b. assign portions of the inventory list to specific inventory teams,
c. compile field observations and reconcile irregularities, and
d. generate the summary report.

2. In-Field Observations App (IFOA): This application is installed on each mobile device. The inventory teams use it to exchange information with the datastore and to record the observations log.

\subsection{OVERALL WORKFLOW}

The overall workflow of the inventory assistant including proposed users, equipment, and software is discussed in the steps described below. Figure 3 provides a key for the symbols used to describe the types information exchanged.

1. The facility operator uses the operator computer to

- Step 1. Upload the inventory list to the datastore ${ }^{6,7}$ (Figure 4)

2. The inventory lead uses DIRA on the office computer to

- Step 2. Download the inventory list from the datastore (Figure 4)

- Step 3. Assign portions of the inventory list to different inventory teams (Figure 4)

- $\quad$ Step 4. Upload the assigned inventory lists to the datastore (Figure 4)

3. Each inventory team uses the IFOA on the mobile device to

- Step 5. Download the assigned inventory list from the datastore (Figure 4)

- Step 6. Record observations. Each observation is time-stamped to create an observations log (Figure 5)

- Step 7. Upload their observations log to the datastore (Figure 5)

\footnotetext{
${ }^{6}$ One implementation approach may be to use a web server (e.g., Internet Information Services, Apache, or Tomcat) to provide an accessible location to store data files from the various components.

${ }^{7}$ Another option to investigate involves creating a capability for the inventory lead to scan and convert a paper copy of the inventory list.
} 
4. Inventory lead uses DIRA on the office computer to

- Step 8. Download the observations logs submitted by the individual inventory teams from the datastore (Figure 5)

- Step 9. Integrate the observations logs with the inventory list and reconcile any irregularities with the inventory teams or operator (Figure 5)

- Step 10. Generate a summary report (Figure 5)

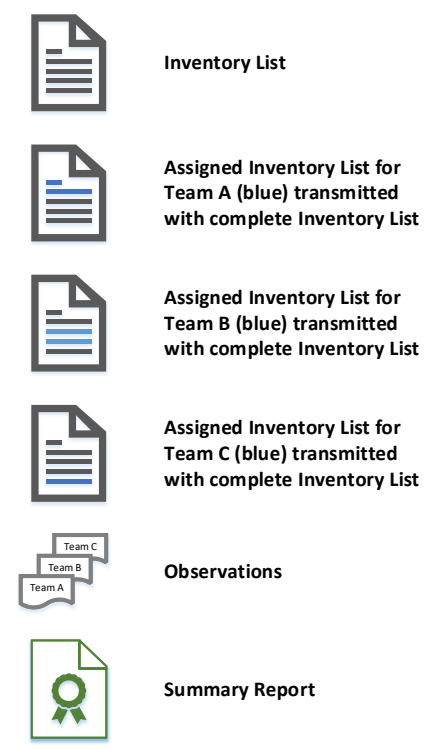

Figure 3. Information exchange key for inventory assistant workflow. 


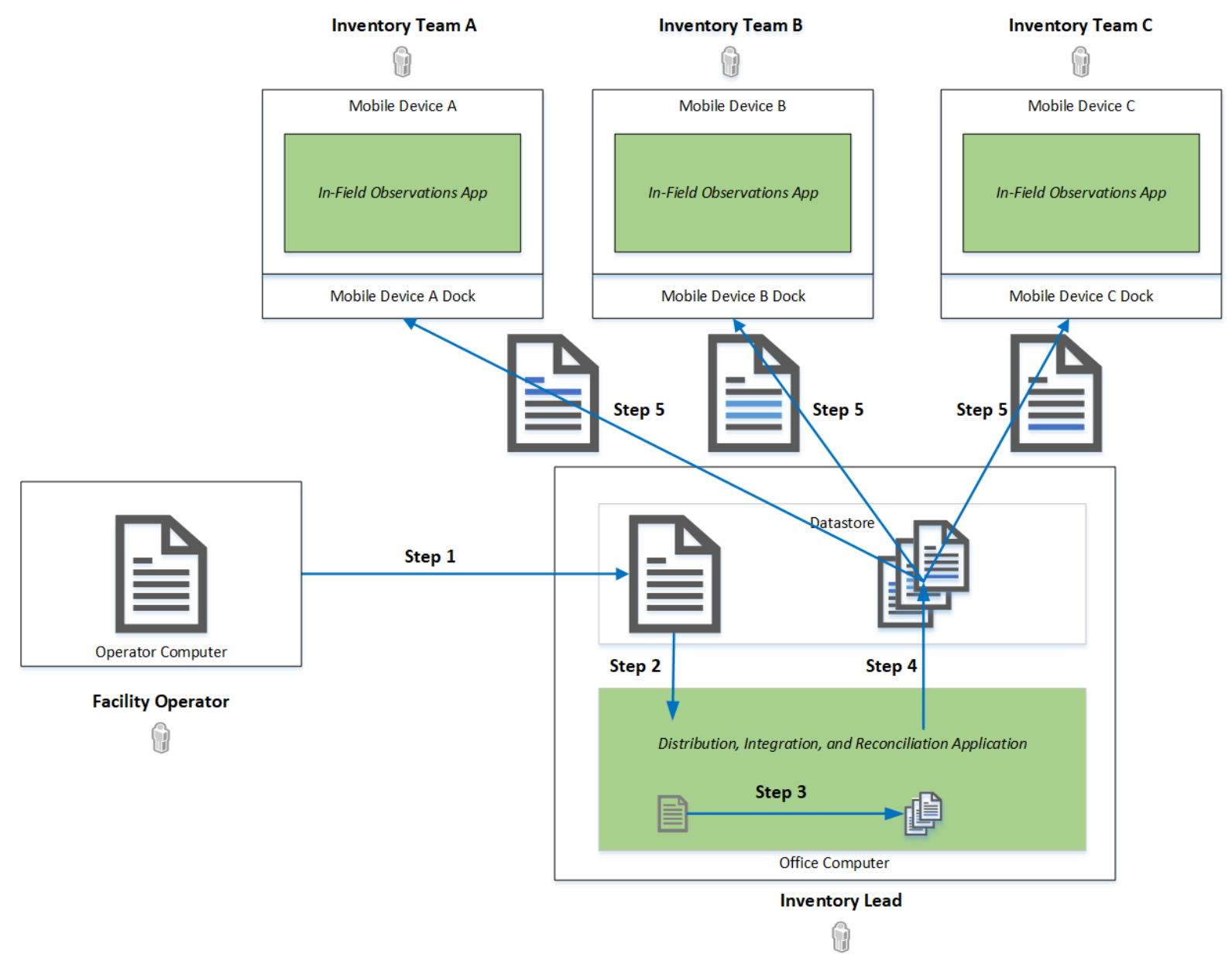

Figure 4. Inventory assistant workflow, steps 1-5. The inventory lead downloads the inventory list on the office computer and then distributes the assigned inventory lists to the mobile devices. 


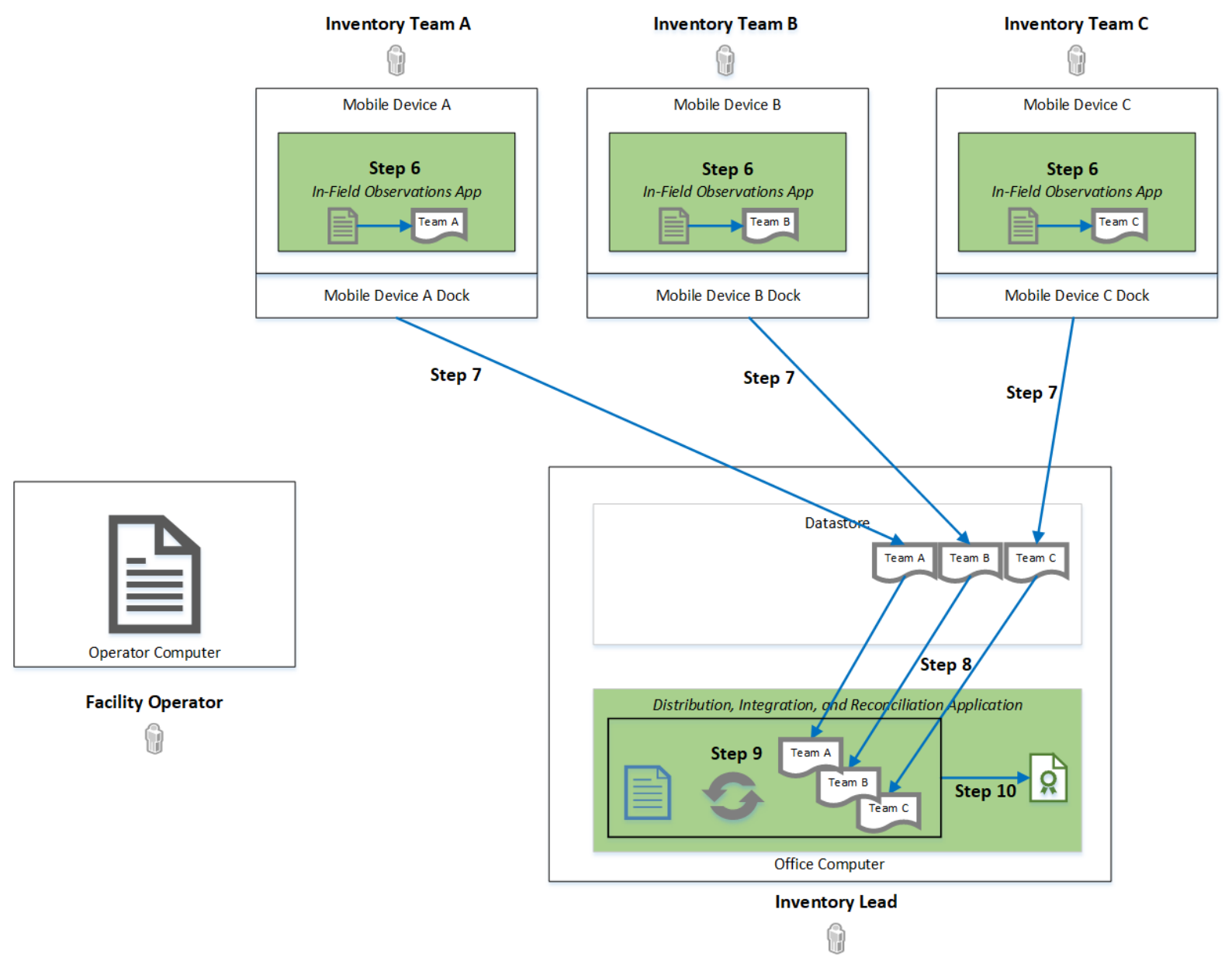

Figure 5. Inventory assistant workflow, steps 6-10. Inventory teams using the mobile devices record timestamped observations. The inventory lead uses DIRA on the office computer to integrate observations with the inventory list, reconcile any irregularities, and generate a summary report. DIRA FUNCTIONALITY

\subsection{OVERVIEW}

As shown in Figure 4 and Figure 5, the inventory lead uses DIRA before and after in-field inventory activities occur. Before the in-field activity, the lead uses DIRA to download the operator-provided inventory list, assign portions of the inventory list to different teams, and distribute these lists to the mobile devices (steps 2-4). After the in-field activity, the lead uses DIRA to collect and integrate all observation logs, reconcile any irregularities with the inventory teams or operators, and generate summary reports (steps 8-10). Potential scenarios encountered by users of DIRA are introduced in Section 5.2 and will be used as example cases throughout this report.

Inventory teams will likely turn in their observations logs together at a predetermined time, such as at the end of the day or at the completion of an inventory. For multiday inventories, it may be beneficial for all teams to upload their observations logs nightly to DIRA such that a partial integration and reconciliation may occur. This would allow the lead to check the overall progress of the inventory as well as potentially flag areas or buildings that need extra attention (e.g., several items in a building were not observed even though all surrounding items were observed). Note observations logs may be partially completed and uploaded to DIRA, all teams must upload their observations logs for the integration process to occur. 
After teams upload their observations logs and the logs are integrated with the inventory list, DIRA assigns a composite observation to an item based on the combination of observations recorded for the item in each team's IFOA. For items with a single observation (e.g., an item observed once in the field in its correct location), the composite observation is equal to the observation recorded in the IFOA. Potential composite observations are described in Section 5.3.1. To flag items with irregularities and to quickly inform the inventory lead about the required resolution activities, each composite observation is associated with a reconciliation status. Potential reconciliation statuses and associated inventory lead actions are described in Section 5.3.2.

Once all reconciliation statuses are computed, the items are initially sorted into two categories: items that require attention from the inventory lead are grouped in the "Needs Action" category; items that do not require attention from the inventory lead are grouped in the "Completed" category. This helps the inventory lead focus on items with irregularities that need to be addressed with the inventory teams or operators and is further discussed in Section 5.3.3. Also discussed in this section is the "Acknowledged" category.

To illustrate the integration process, the in-field scenarios introduced in Section 5.2 are more thoroughly addressed in Section 5.4. Potential actions taken by the inventory teams, the resulting observations recorded in the IFOA, the assigned composite observation and reconciliation status after integration, and the required inventory lead actions are discussed for each scenario.

Depending upon the reconciliation status and the inventory lead's actions, after an item in the Needs Action category is addressed, it is moved to the Acknowledged or Completed category. The required reconciliation processes and outcomes are discussed in Section 5.5. After the inventory lead reconciles all items (i.e., all items are removed from the Needs Action category), the lead finalizes or locks the inventory, which will lock the observations and inventory lead actions such that they cannot be changed. The lead may also generate a summary report highlighting items that required acknowledgment or resolution and displaying comments added about the reconciliation activities. The summary report can be printed as needed to distribute to the inventory teams or operators (e.g., at the end of the day during a multiday activity).

\subsection{INTRODUCTION TO REPRESENTATIVE SCENARIOS}

The authors anticipate that most if not all in-field observations will be made by the assigned team; however, the real power of the inventory assistant is its ability to handle spurious cases. Since the items on the operator-provided inventory list are distributed among multiple inventory teams and in-field observations are not synchronized in real time, multiple teams may enter observations about the same item without knowing another team's actions. Reflecting this possibility, the following scenarios are representative of potential scenarios that users could encounter. We will refer to the following potential in-field scenarios throughout the remainder of this paper:

1. Item assigned to Team A is only observed by Team A

2. Item assigned to Team B is only observed by Team A

3. Team A inadvertently records an observation about an item and then revises the observation. Team A later sees that item in the field and records an observation.

4. Assigned item is not observed by any team.

5. An item not on the inventory list is observed in the field by Team A and is added to the list. 
6. Team A observes an item and then later observes a different item with the same identification number in a different location. Team A manually adds that item to the list as a duplicate.

7. Team A inadvertently observes the same item twice and manually adds the second observation to the list as a duplicate.

8. Team A observes assigned item once. Team B observes a different item with the same identification number in a different location. Duplication is not known by either team until after the integration process.

9. Team A observes assigned item once. Team B enters Team A's assigned portion of the building and observes the same item. Duplication is not known by either team until after the integration process.

10. Team A types the wrong identification number during a manual search. This identification number was not on the inventory list and Team A subsequently adds an incorrect item to the list. No observation is recorded for the item actually observed in the field.

11. Team A inadvertently records an observation (e.g., swiped right) for the wrong identification number and did not notice. When Team A reaches the identification number of the inadvertently observed item, they manually search for it and add the item as a duplicate. Original item is not observed.

\subsection{INTEGRATE THE OBSERVATIONS LOGS}

\subsubsection{Composite Observation}

DIRA is designed to integrate all observations for each item after the individual observations logs are downloaded from the datastore. For items with multiple observations recorded in the field, the application computes a composite observation based on the combination of field observations. For example, if Item X is observed once by Team A and once by Team B, then Item X has two observations associated with it. These observations will be sorted by time, and a composite observation will be computed based on the combination of the two observations. For items with a single observation, the composite observation is equal to the observation recorded on the IFOA. Composite observations are listed in Table 1.

Table 1. Composite observations.

\begin{tabular}{l}
\hline \multicolumn{1}{c}{ Composite Observation } \\
\hline Observed \\
Not Observed \\
Added to List \\
Duplicate - Within Team \\
Duplicate - Multiple Teams \\
\hline
\end{tabular}

\subsubsection{Reconciliation Status}

Next, DIRA computes a reconciliation status based on an item's composite observation. This allows the inventory lead to quickly prioritize items that need reconciliation, which is particularly useful for large facilities that may have thousands of items. There are three reconciliation status options for an item and each has an associated inventory lead action (Table 2). Items with the "Information" status do not require action from the lead. 
Table 2. Reconciliation status with associated inventory lead action.

\begin{tabular}{|c|c|c|}
\hline \multicolumn{2}{|c|}{ Reconciliation Status } & \multirow{2}{*}{ Inventory Lead Action } \\
\hline Term & Symbol & \\
\hline Information & ( & Not required \\
\hline Warning & 祡 & $\begin{array}{l}\text { Required - must acknowledge by reviewing comments or discussing with inventory } \\
\text { team }\end{array}$ \\
\hline Error & $\mathbf{A}$ & $\begin{array}{l}\text { Required-must investigate by entering reconciliation process and discussing with } \\
\text { operator and inventory team }\end{array}$ \\
\hline
\end{tabular}

\subsubsection{Category}

All items that were observed in the field or are on the operator-provided inventory list are displayed in three main categories:

- Needs Action: This category contains items with a "warning" or an "error" reconciliation status as defined in Table 2. For items with a warning status, the inventory lead must review comments or discuss them with the inventory team. For items with an error status, the inventory lead must enter the reconciliation process and investigate with the operator and the inventory team.

- $\quad$ Acknowledged: This category is initially empty.

- Completed: This category contains items that are observed once by the assigned inventory team. These items do not require any further action by the inventory lead (i.e., no questions were raised by the observation).

For each composite observation, the associated reconciliation status, initial item category, and inventory lead action are presented in Table 3. 
Table 3. DIRA-assigned reconciliation status and required inventory lead actions for each composite observation.

\begin{tabular}{|c|c|c|c|c|}
\hline \multirow{2}{*}{$\begin{array}{c}\text { Composite } \\
\text { observation }\end{array}$} & \multicolumn{2}{|c|}{ Reconciliation Status } & \multirow{2}{*}{$\begin{array}{c}\text { Initial Item Category } \\
\text { (Needs Action or Completed) }\end{array}$} & \multirow{2}{*}{ Inventory Lead Action } \\
\hline & Term & Symbol & & \\
\hline \multirow[b]{2}{*}{ Observed } & Information & ( & Completed & Not required \\
\hline & Warning & $=$ & Needs Action & $\begin{array}{l}\text { Required-must acknowledge } \\
\text { by reviewing comments or } \\
\text { discussing with inventory team }\end{array}$ \\
\hline Not Observed & Error & $\mathbf{A}$ & \multirow{4}{*}{ Needs Action } & \multirow{4}{*}{$\begin{array}{l}\text { Required-must investigate by } \\
\text { entering reconciliation process } \\
\text { and discussing with operator } \\
\text { and inventory team }\end{array}$} \\
\hline Added to List & Error & $\mathbf{A}$ & & \\
\hline $\begin{array}{l}\text { Duplicate- } \\
\text { Within Team }\end{array}$ & Error & $\mathbf{A}$ & & \\
\hline $\begin{array}{c}\text { Duplicate- } \\
\text { Multiple Teams }\end{array}$ & Error & $\mathbf{A}$ & & \\
\hline
\end{tabular}

As the reconciliation activities described in Section 5.5 occur, these three categories will change as follows:

- Needs Action: As items with a warning or error status are acknowledged or resolved by the inventory lead, they are removed from this category.

- Acknowledged: As items with a warning or error status are acknowledged by the inventory lead, they move from the Needs Action to the Acknowledged category.

- Completed: As items with an error status are resolved by the inventory lead, they move from the Needs Action to the Completed category. Items that are observed once by the assigned inventory team and required no inventory lead action remain in the Completed category.

The ORNL team envisions that all items with irregularities must be either acknowledged or resolved to finalize an inventory's reconciliation process. This means that the inventory lead cannot finalize the inventory until the Needs Action category is empty. If an item cannot be resolved after speaking with the operator and the inventory teams, the item will remain in the Needs Action category indefinitely until new information is collected and the inventory lead is able to acknowledge or resolve the item.

\subsection{POTENTIAL IN-FIELD SCENARIOS WITH COMPOSITE OBSERVATION, RECONCILIATION STATUS, AND CATEGORY}

To better illustrate the integration process, the in-field scenarios introduced in Section 5.2 are further described in Table 4 with the potential actions taken by the inventory teams in the field, the resulting observations recorded in the IFOA, the DIRA-computed composite observation and reconciliation status after integration, and the required inventory lead actions. Items with a warning or error reconciliation status are initially assigned to the Needs Action category, whereas items with an information reconciliation status are initially assigned to the Completed category. 
Table 4. Potential in-field scenarios, associated actions by the inventory team, and DIRA-assigned composite observations and reconciliation status.

\begin{tabular}{|c|c|c|c|c|c|c|c|c|}
\hline \multirow{3}{*}{ Scenario } & \multicolumn{5}{|c|}{ After Assigned Inventory List Distribution, Before Integration } & \multicolumn{3}{|c|}{ After Integration } \\
\hline & \multirow{2}{*}{$\begin{array}{l}\text { Assigned } \\
\text { Team }\end{array}$} & \multirow{2}{*}{$\begin{array}{l}\text { Team that } \\
\text { Observed }\end{array}$} & \multirow{2}{*}{ In-field Scenario } & \multirow{2}{*}{ Inventory Team Actions } & \multirow{2}{*}{$\begin{array}{c}\text { Observations Recorded } \\
\text { on IFOA }\end{array}$} & \multirow{2}{*}{$\begin{array}{l}\text { Composite } \\
\text { Observation }\end{array}$} & \multicolumn{2}{|c|}{$\begin{array}{c}\text { Reconciliation } \\
\text { Status }\end{array}$} \\
\hline & & & & & & & Term & Symbol \\
\hline 1 & A & \multirow[b]{3}{*}{ A } & \multirow[b]{2}{*}{ Item only observed by Team A } & \multirow{2}{*}{$\begin{array}{l}\text { 1. Team A swipes right, types the } \\
\text { item identification number into } \\
\text { the search bar and swipes right, } \\
\text { or scans barcode matching an } \\
\text { item identification number }\end{array}$} & Team A: Observed & \multirow[b]{3}{*}{ Observed } & Info & ( \\
\hline 2 & B & & & & $\begin{array}{l}\text { Team A: Observed - } \\
\text { Wrong Team } \\
\text { Team B: Not Confirmed }\end{array}$ & & \multirow[b]{2}{*}{ Warn } & \multirow[b]{2}{*}{ 帮 } \\
\hline 3 & A & & $\begin{array}{l}\text { Team A inadvertently records an } \\
\text { observation about an item and } \\
\text { then revises the observation. } \\
\text { Team A later sees that item in } \\
\text { the field and records an } \\
\text { observation. }\end{array}$ & \begin{tabular}{|l|} 
1. \\
Team A swipes right or \\
searches + swipes right \\
2. Swipes left to revise \\
observation \\
3. Swipes right, searches + \\
swipes right, or scans barcode \\
\end{tabular} & $\begin{array}{l}\text { Team A: (1) item with } \\
\text { 1. Observed } \\
\text { 2. Revised a Selection } \\
\text { 3. Observed }\end{array}$ & & & \\
\hline 4 & A & None & Item not observed by any team. & 1. No action & All Teams: Not Observed & Not Observed & Error & $\mathbf{A}$ \\
\hline 5 & None & A & $\begin{array}{l}\text { An item not on the inventory list } \\
\text { is observed in the field by Team } \\
\text { A and is added to the list. }\end{array}$ & $\begin{array}{l}\text { 1. Team A manually searches for } \\
\text { item, but it is not on the list } \\
\text { 2. Item is manually added to the } \\
\text { inventory list }\end{array}$ & Team A: Added to List & Added to List & Error & $\mathbf{A}$ \\
\hline 6 & \multirow{2}{*}{ A } & \multirow{2}{*}{ A } & $\begin{array}{l}\text { Team A observes an item and } \\
\text { then later observes a different } \\
\text { item with the same identification } \\
\text { number in a different location. } \\
\text { Team A manually adds that item } \\
\text { to the list as a duplicate. }\end{array}$ & \multirow{2}{*}{$\begin{array}{l}\text { 1. Team A swipes right, searches } \\
\text { + swipes right, or scans } \\
\text { barcode once } \\
\text { 2. Item with the same } \\
\text { identification number is then } \\
\text { manually added as duplicate }\end{array}$} & \multirow{2}{*}{$\begin{array}{l}\text { Team A: (1) item with } \\
\text { 1. Observed } \\
\text { 2. Duplicate-Within } \\
\text { Team }\end{array}$} & \multirow{2}{*}{$\begin{array}{l}\text { Duplicate - } \\
\text { Within Team }\end{array}$} & \multirow{2}{*}{ Error } & \multirow{2}{*}{$\mathbf{A}$} \\
\hline 7 & & & $\begin{array}{l}\text { Team A inadvertently observes } \\
\text { the same item twice and } \\
\text { manually adds the second } \\
\text { observation to the list as a } \\
\text { duplicate. }\end{array}$ & & & & & \\
\hline
\end{tabular}


Table 4. Potential in-field scenarios, associated actions by the inventory team, and DIRA-assigned composite observations and reconciliation status, continued.

\begin{tabular}{|c|c|c|c|c|c|c|c|c|}
\hline \multirow{3}{*}{ Scenario } & \multicolumn{5}{|c|}{ After Assigned Inventory List Distribution, Before Integration } & \multicolumn{3}{|c|}{ After Integration } \\
\hline & \multirow{2}{*}{$\begin{array}{l}\text { Assigned } \\
\text { Team }\end{array}$} & \multirow{2}{*}{$\begin{array}{c}\text { Team } \\
\text { that } \\
\text { Observed }\end{array}$} & \multirow{2}{*}{ In-field Scenario } & \multirow{2}{*}{ Inventory Team Actions } & \multirow{2}{*}{$\begin{array}{c}\text { Observations } \\
\text { Recorded on IFOA }\end{array}$} & \multirow{2}{*}{$\begin{array}{l}\text { Composite } \\
\text { Observation }\end{array}$} & \multicolumn{2}{|c|}{$\begin{array}{c}\text { Reconciliation } \\
\text { Status }\end{array}$} \\
\hline & & & & & & & Term & Symbol \\
\hline 8 & \multirow[t]{2}{*}{ A } & \multirow[t]{2}{*}{$\mathrm{A}$ and $\mathrm{B}$} & $\begin{array}{l}\text { Team A observes assigned item } \\
\text { once. Team B observes a } \\
\text { different item with the same } \\
\text { identification number in a } \\
\text { different location. Duplication } \\
\text { is not known by either team } \\
\text { until after the integration } \\
\text { process. }\end{array}$ & \multirow{2}{*}{$\begin{array}{l}\text { 1. Team A and Team B both } \\
\text { swipe right, search }+ \text { swipe } \\
\text { right, or scan barcode once }\end{array}$} & \multirow{2}{*}{$\begin{array}{l}\frac{\text { Team A: }}{\text { Team B }} \text { : Observed } \\
\text { Wrong Team }\end{array}$} & \multirow{2}{*}{$\begin{array}{c}\text { Duplicate - } \\
\text { Multiple Teams }\end{array}$} & \multirow[t]{2}{*}{ Error } & \multirow[t]{2}{*}{$\Delta$} \\
\hline 9 & & & $\begin{array}{l}\text { Team A observes assigned item } \\
\text { once. Team B enters Team A's } \\
\text { assigned portion of the building } \\
\text { and observes the same item. } \\
\text { Duplication is not known by } \\
\text { either team until after the } \\
\text { integration process. }\end{array}$ & & & & & \\
\hline 10 & A & A & $\begin{array}{l}\text { Team A types the wrong } \\
\text { identification number during a } \\
\text { manual search. This } \\
\text { identification number was not } \\
\text { on the inventory list and Team } \\
\text { A subsequently adds an } \\
\text { incorrect item to the list. No } \\
\text { observation is recorded for the } \\
\text { item actually observed in the } \\
\text { field. }\end{array}$ & $\begin{array}{l}\text { 1. Team A manually searches } \\
\text { for item, but it is not on the } \\
\text { list } \\
\text { 2. Item is manually added to the } \\
\text { inventory list } \\
\text { 3. Intended item has no recorded } \\
\text { observation }\end{array}$ & $\begin{array}{l}\text { Team A: } \\
\text { (1) item }- \text { Added to List } \\
\text { (1) item - Not } \\
\text { Observed }\end{array}$ & $\begin{array}{l}\text { 1. Added to List } \\
\text { 2. Not Observed }\end{array}$ & $\begin{array}{l}(2) \\
\text { Errors }\end{array}$ & $\mathbf{A}$ \\
\hline 11 & A & A & $\begin{array}{l}\text { Team A inadvertently records } \\
\text { an observation (e.g., swiped } \\
\text { right) for the wrong } \\
\text { identification number and did } \\
\text { not notice. When Team A } \\
\text { reaches the identification } \\
\text { number of the inadvertently } \\
\text { observed item, they manually } \\
\text { search for it and add the item as } \\
\text { a duplicate. Original item is not } \\
\text { observed. }\end{array}$ & $\begin{array}{l}\text { 1. Team A swipes right on the } \\
\text { wrong identification number } \\
\text { and did not notice } \\
\text { 2. Item with the same } \\
\text { identification number is then } \\
\text { manually added as duplicate } \\
\text { 3. Intended item has no recorded } \\
\text { observation }\end{array}$ & $\begin{array}{l}\text { Team A: } \\
\text { (1) item - Duplicate - } \\
\text { Within Team } \\
\text { (1) item - Not } \\
\text { Observed }\end{array}$ & $\begin{array}{l}\text { 1. Duplicate - } \\
\text { Within Team } \\
\text { 2. Not Observed }\end{array}$ & $\begin{array}{l}(2) \\
\text { Errors }\end{array}$ & $\mathbf{A}$ \\
\hline
\end{tabular}




\subsection{RECONCILIATION PROCESS}

\subsubsection{No Action Required}

As previously mentioned, items that are observed in the field by the assigned team appear in the Completed category and do not require any further action by the inventory lead (i.e., no questions were raised by the observation). The composite observation and reconciliation status for these items are "Observed" and "Information," respectively (Table 3). The only scenario encountered in the field that requires no action by the inventory lead is described by scenario 1 in Table 4, which is when the assigned inventory team observed the item once. A summary of the process for items that require no action is included in Table 5.

\subsubsection{Acknowledge a Warning}

As shown in Table 3, DIRA assigns a "warning" reconciliation status to certain items that are Observed. Potential in-field scenarios that result in a warning status are described by scenarios 2 and 3 in Table 4 . In scenario 2, the wrong team observed the item once in the field, and in scenario 3, the correct team observed the item, but there was a manual revision to an observation at some point in the item's history (e.g., the team swiped left). Items with a warning status appear in the Needs Action category and must be acknowledged by the inventory lead. To acknowledge a warning for an observed item, the inventory lead views the item's observations on the main page, reads any associated comments, and discusses with the inventory team. Once acknowledged, the selected item is moved from the Needs Action to the Acknowledged category, and the composite observation does not change. The inventory lead remains on the main screen during the entire acknowledgment process and does not need to add any comments. A summary of the process to acknowledge a warning is included in Table 6.

\subsubsection{Acknowledge or Resolve an Error}

As shown in Table 3, DIRA assigns an "error" reconciliation status to items with any composite observation that is not Observed. Potential in-field scenarios that result in an error status are described in Table 4 and include examples such as not observing an item on the inventory list in the field (scenario 4), observing an item in the field that is not on the inventory list (scenario 5), observing distinct items with the same identification number (scenarios 6 and 8), and observing the same item more than once (scenarios 7 and 9). Additionally, more complicated scenarios such as accidentally entering observations for unintended items (scenarios 10 and 11) would result in multiple items with an error status. Items with an error status appear in the Needs Action category and must be acknowledged or resolved by the inventory lead. Because this process is more complicated and varied than the process discussed in Section 5.5.2, the inventory lead is routed to a separate reconciliation page to proceed. On the reconciliation page, all information for a selected item is automatically expanded and displayed in addition to all other items with an error reconciliation status.

To acknowledge an error, the inventory lead must speak with the operator and the inventory team to determine the cause of the error. If found, the inventory lead adds a descriptive comment and acknowledges the error. Once acknowledged, the item is moved from the Needs Action to the Acknowledged category. Similar to acknowledging a warning, the composite observation of the item does not change after an error is acknowledged. A summary of the process to acknowledge an error is included in Table 7.

To resolve an error, the inventory lead must speak with the operator and inventory team to determine the cause of the error. If found, the lead must match the selected item with another item or observation that 
needs action and add a comment. Once resolved, the items are moved from the Needs Action to the Completed category, and the composite observations are changed to Observed. Unlike acknowledging a warning or an error, this process removes at least two items from the Needs Action category and the composite observation for each item changes. A summary of the process to resolve an error is included in Table 8. 
Table 5. No action required.

\begin{tabular}{|c|c|c|c|c|c|c|}
\hline Category & $\begin{array}{c}\text { Composite } \\
\text { Observation }\end{array}$ & Potential Root Cause & How to Identify & Reconciliation? & Category & $\begin{array}{c}\text { Composite } \\
\text { Observation }\end{array}$ \\
\hline Completed & Observed & None - Scenario 1 , Table 4 & (1) Observed item & 1. None required & Completed & Observed \\
\hline
\end{tabular}

Table 6. Process to acknowledge a warning.

\begin{tabular}{|c|c|c|c|c|c|c|}
\hline \multicolumn{4}{|c|}{ Before Acknowledgement } & \multirow[b]{2}{*}{ Acknowledgement } & \multicolumn{2}{|c|}{ After Acknowledgement } \\
\hline Category & $\begin{array}{c}\text { Composite } \\
\text { Observation }\end{array}$ & Potential Root Cause & How to Identify & & Category & $\begin{array}{c}\text { Composite } \\
\text { Observation }\end{array}$ \\
\hline \multirow{2}{*}{$\begin{array}{l}\text { Needs } \\
\text { Action }\end{array}$} & \multirow{2}{*}{ Observed } & Accidental - Scenario 2, Table 4 & $\begin{array}{l}\text { (1) Observed item with (1) } \\
\text { Observed - Wrong Team field } \\
\text { observation }\end{array}$ & \multirow{2}{*}{$\begin{array}{l}\text { 1. Look at observations } \\
\text { 2. Discuss with team } \\
\text { 3. Select "Acknowledge" on } \\
\text { main page }\end{array}$} & \multirow{2}{*}{ Acknowledged } & \multirow{2}{*}{ Observed } \\
\hline & & Accidental - Scenario 3, Table 4 & $\begin{array}{l}\text { (1) Observed item with at least (1) } \\
\text { Revised a Selection field } \\
\text { observation }\end{array}$ & & & \\
\hline
\end{tabular}

Table 7. Process to acknowledge an error.

\begin{tabular}{|c|c|c|c|c|c|c|}
\hline \multicolumn{4}{|c|}{ Before Acknowledgement } & \multirow[b]{2}{*}{ Acknowledgement } & \multicolumn{2}{|c|}{ After Acknowledgement $^{8}$} \\
\hline Category & $\begin{array}{c}\text { Composite } \\
\text { observation }\end{array}$ & Potential Root Cause & How to Identify & & Category & $\begin{array}{c}\text { Composite } \\
\text { observation }\end{array}$ \\
\hline \multirow{6}{*}{$\begin{array}{l}\text { Needs } \\
\text { Action }\end{array}$} & Not Observed & $\frac{\text { Operator error }}{\text { Table } 4}$ - Scenario 4, & (1) Not Observed item & \multirow{6}{*}{$\begin{array}{l}\text { 1. Open reconciliation screen } \\
\text { 2. Speak with operator/team } \\
\text { 3. Add explanatory comment } \\
\text { 4. Select Acknowledge }\end{array}$} & \multirow{6}{*}{ Acknowledged } & Not Observed \\
\hline & Added to List & $\frac{\text { Operator error }}{\text { Table } 4}$ - Scenario 5, & (1) Added to List item & & & Added to List \\
\hline & $\begin{array}{c}\text { Duplicate - } \\
\text { Within Team }\end{array}$ & $\frac{\text { Operator error }}{\text { Table } 4}$ - Scenario 6, & $\begin{array}{l}\text { (1) Duplicate - Within } \\
\text { Team item }\end{array}$ & & & $\begin{array}{c}\text { Duplicate - } \\
\text { Within Team }\end{array}$ \\
\hline & $\begin{array}{c}\text { Duplicate - } \\
\text { Multiple Teams }\end{array}$ & $\frac{\text { Operator error }- \text { Scenario } 8,}{\text { Table } 4}$ & $\begin{array}{l}\text { (1) Duplicate-Multiple } \\
\text { Teams item }\end{array}$ & & & $\begin{array}{c}\text { Duplicate - } \\
\text { Multiple Teams }\end{array}$ \\
\hline & $\begin{array}{c}\text { Duplicate - } \\
\text { Within Team } \\
\end{array}$ & $\frac{\text { Accidental }}{\text { Table } 4}-$ Scenario 7 & $\begin{array}{l}\text { (1) Duplicate - Within } \\
\text { Team item }\end{array}$ & & & $\begin{array}{c}\text { Duplicate - } \\
\text { Within Team }\end{array}$ \\
\hline & $\begin{array}{c}\text { Duplicate - } \\
\text { Multiple Teams }\end{array}$ & $\frac{\text { Accidental }}{\text { Table } 4}$ - Scenario 9, & $\begin{array}{l}\text { (1) Duplicate-Multiple } \\
\text { Teams item }\end{array}$ & & & $\begin{array}{c}\text { Duplicate - } \\
\text { Multiple Teams }\end{array}$ \\
\hline
\end{tabular}

\footnotetext{
${ }^{8}$ Note that the composite observation does not change after acknowledging an error.
} 
Table 8. Process to resolve an error.

\begin{tabular}{|c|c|c|c|c|c|c|}
\hline \multicolumn{4}{|c|}{ Before Resolution } & \multirow[b]{2}{*}{ Resolution } & \multicolumn{2}{|c|}{ After Resolution' } \\
\hline Category & $\begin{array}{l}\text { Composite } \\
\text { Observation }\end{array}$ & Potential Root Cause & How to Identify & & Category & $\begin{array}{c}\text { Composite } \\
\text { Observation }\end{array}$ \\
\hline $\begin{array}{l}\text { Needs } \\
\text { Action }\end{array}$ & Not Observed & $\underline{\text { Typo }}$ - Scenario 10, Table 4 & $\begin{array}{l}\text { (1) Not Observed item } \\
\text { (1) Added to List item }\end{array}$ & $\begin{array}{l}\text { 1. Open reconciliation screen } \\
\text { for not observed item } \\
\text { 2. Speak with operator } \\
\text { 3. Select added to list item } \\
\text { from Needs Action on } \\
\text { reconciliation page } \\
\text { 4. Add explanatory comment } \\
\text { 5. Select "Resolve" to merge } \\
\text { items }\end{array}$ & Completed & $\begin{array}{l}\text { (1) Observed } \\
\text { item }\end{array}$ \\
\hline $\begin{array}{l}\text { Needs } \\
\text { Action }\end{array}$ & $\begin{array}{l}\text { Not Observed } \\
\end{array}$ & $\frac{\text { Accidental }}{\text { Table } 4}-$ Scenario 11, & $\begin{array}{l}\text { (1) Not Observed item } \\
\text { (1) Duplicate - Within } \\
\text { Team item }\end{array}$ & $\begin{array}{l}\text { 1. Open reconciliation screen } \\
\text { for duplicate - within team } \\
\text { item } \\
\text { 2. Speak with operator } \\
\text { 3. Select appropriate } \\
\text { observation under duplicate } \\
\text { - within team item } \\
\text { 4. Select not observed item } \\
\text { from Needs Action on } \\
\text { reconciliation screen } \\
\text { 5. Add explanatory comment } \\
\text { 6. Select Resolve to merge } \\
\text { appropriate observation } \\
\text { under duplicate - within } \\
\text { team item with not } \\
\text { observed item }\end{array}$ & Completed & $\begin{array}{l}\text { (2) Observed } \\
\text { items }\end{array}$ \\
\hline
\end{tabular}

\footnotetext{
${ }^{9}$ Note, the composite observation changes to Observed after resolving an error.
} 


\section{DIRA USER EXPERIENCE}

\subsection{OVERVIEW}

The following sections describe how the inventory lead uses DIRA both before and after in-field inventory activities to reconcile the in-field observations with the operator-provided listing. Example screens are provided to illustrate how the inventory lead steps through the full inventory assignment and reconciliation process. Note, these screens are conceptual in nature and do not describe every potential irregularity that can be experienced by the inventory lead.

\subsection{START NEW INVENTORY}

Upon starting DIRA on the office computer, the inventory lead is presented with the option to start a new inventory, view a completed inventory, or resume an in-progress inventory (Figure 6). If starting a new inventory, the inventory lead selects a prepopulated facility from the dropdown list or adds a new facility (Figure 7). Afterward, the lead browses their files to upload a digital copy of the operator-provided inventory list to DIRA (Figure 8). 


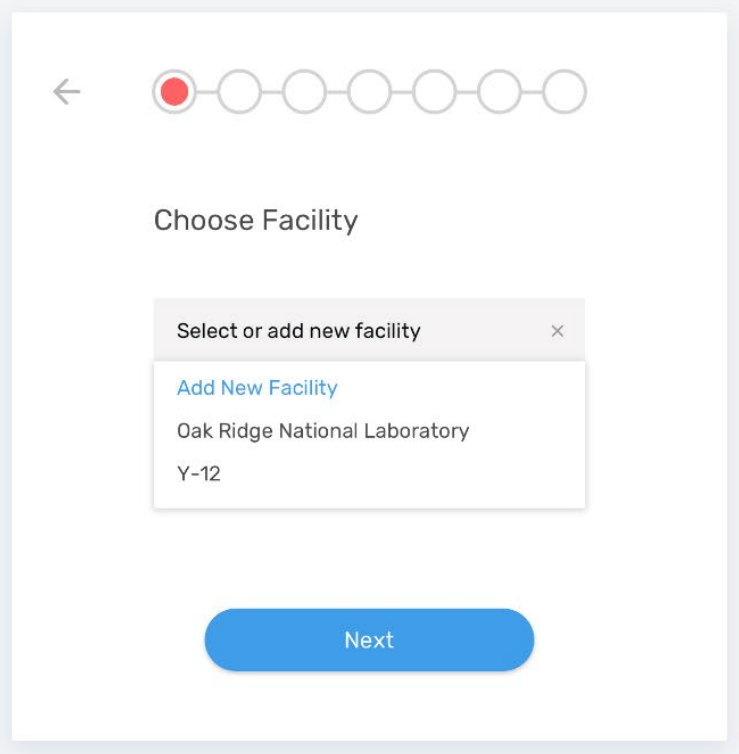

Figure 7. Select or add a facility for a new inventory activity.

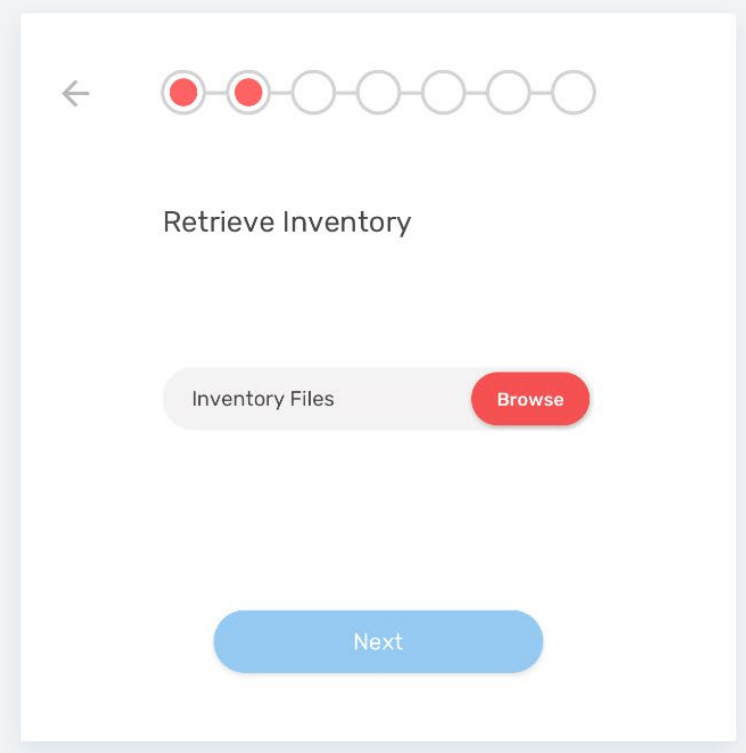

Figure 8. Browse files to upload the operator-provided inventory list. 
If viewing a completed inventory, the lead selects the facility and time period for the inventory of interest to view the final summary report (Figure 9).
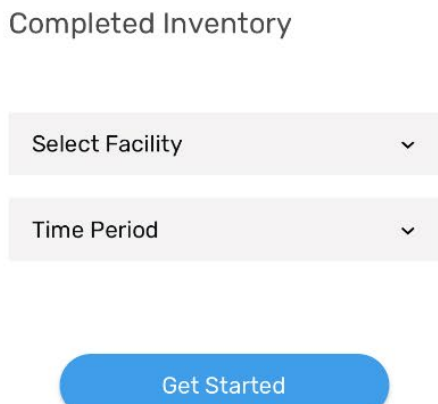

Figure 9. Select facility and time period to view the summary report for a completed inventory activity.

Depending upon the size of the facility and the number of inventory teams, an inventory activity may take multiple days to complete. In this case, an inventory lead may ask the teams to periodically upload their observations logs, even if the team has not completed its assigned inventory list (e.g., at the end of the day). To resume an inventory (e.g., at the beginning of a new inventory day), the lead is prompted to select the facility and time period for the inventory of interest to view the field observation activities in progress page (Figure 10).

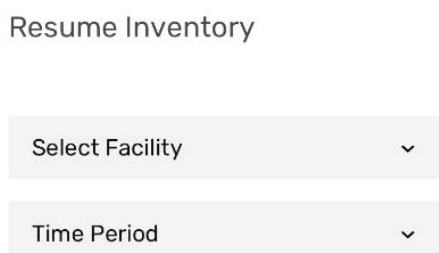

Get Started

Figure 10. Select facility and time period to resume an inventory activity. 


\subsection{CREATE INVENTORY TEAMS}

After selecting a digital copy of the inventory list, the inventory lead is prompted to create the inventory teams (Figure 11). On this page, the lead selects or adds multiple inspectors to a single team, as well as assigns a single mobile device to each team for the entirety of the inventory activity. The lead may also create multiple teams on this page by selecting the "Add New Team" tile. The "Next" button is disabled until at least one team is created.

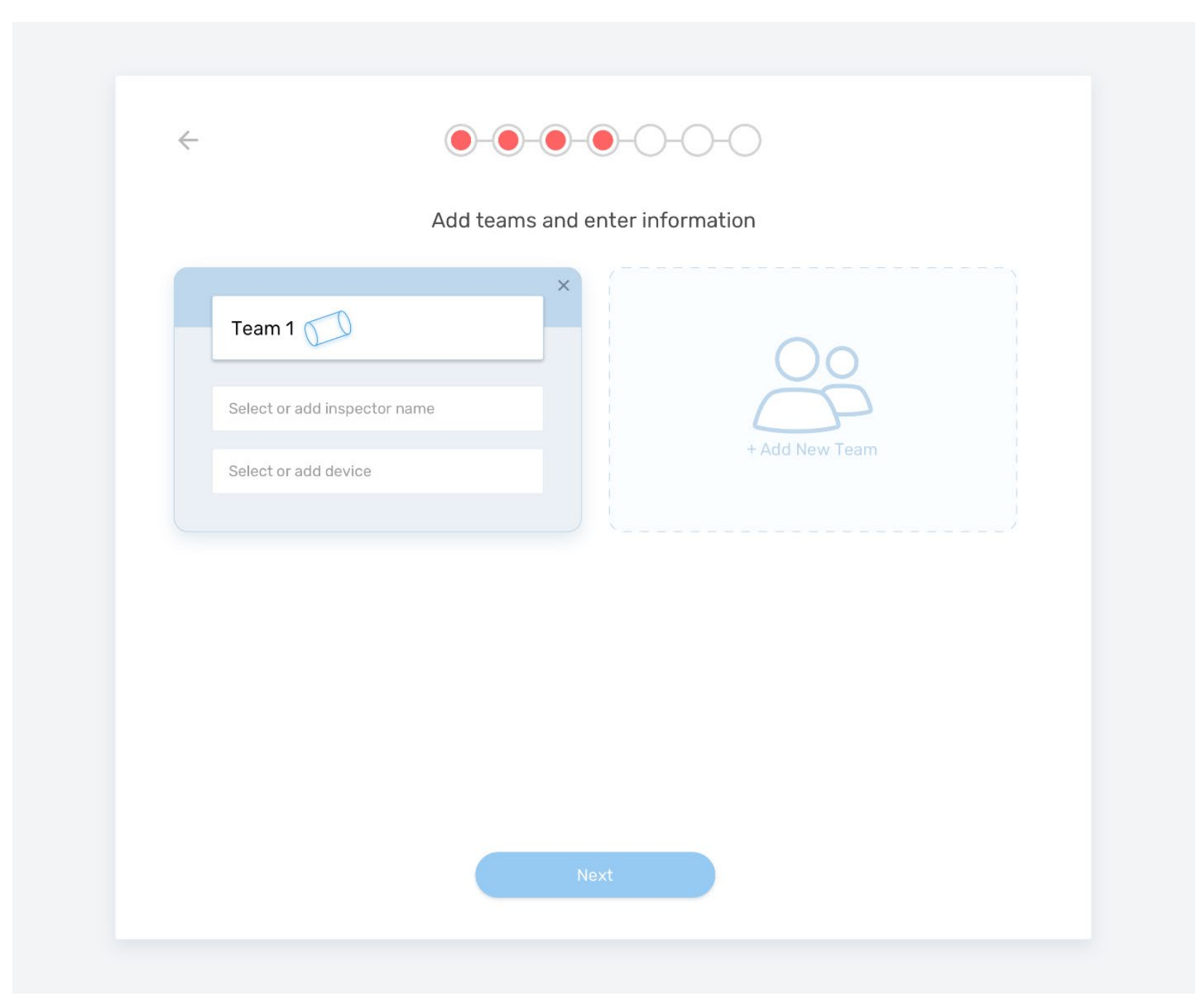

Figure 11. Create an inventory team.

\subsection{ASSIGN ITEMS}

After creating one or more inventory teams, the inventory lead assigns portions of the inventory list to the individual teams. To save time, the lead is first prompted to assign a percentage of the total inventory to each team. As a starting suggestion, the inventory is evenly distributed between each team, but the inventory lead may type in a desired percentage. If the sum of the distributed percentages is greater than $100 \%$, a warning is displayed, and the inventory lead must adjust the entries. If the sum of the distributed percentages is less than or equal to $100 \%$, the Next button is enabled, and the inventory lead may proceed. 
As shown in Figure 12, the inventory lead assigns each team $25 \%$ of the total inventory to start. After selecting the Next button, DIRA automatically selects and assigns approximately $25 \%$ of the total inventory to each team. Note, the inventory lead may change the DIRA-selected assignments during the manual assignment screen shown later. Additionally, if the inventory lead wishes to manually assign all the items without taking DIRA's automatic selections into account, the lead can enter $0 \%$ for each of the teams in Figure 12.

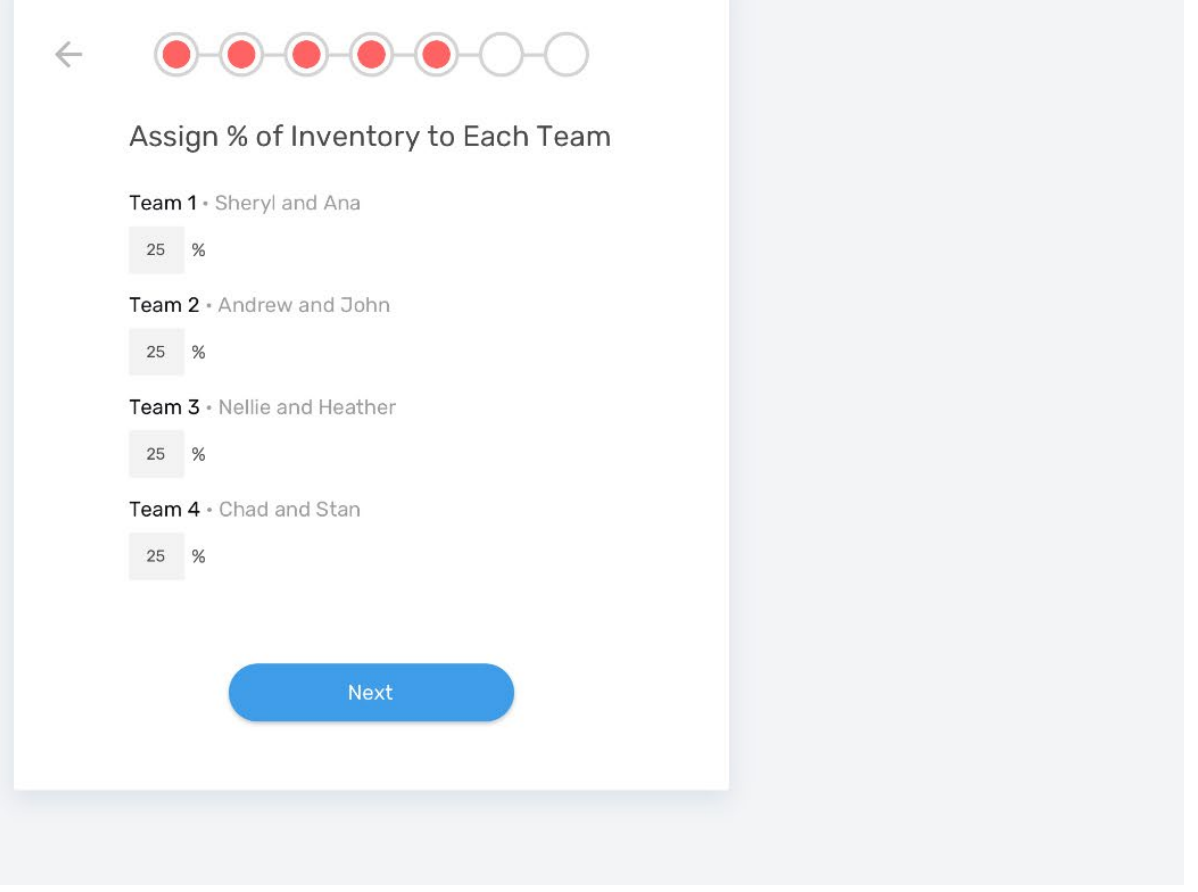

Figure 12. Assign a percentage of the inventory list to each team.

After selecting Next, the operator-provided inventory list is displayed by the level 0 (building) and level 1 (row) hierarchy as shown in Figure 13 [1]. All building and row headers display the total number of items to observe and may be expanded to view the individual item identification numbers and locations (Figure 14). Cylinders will be assigned to teams starting with Team 1 up to their assigned percentage of inventory, followed by Team 2 up to their assigned percentage, until each team has been assigned their prescribed percentage of items. If less than $100 \%$ of the inventory was assigned, a count of the unassigned items will be shown as "remaining unassigned items," and no boxes or radio buttons would be selected for those items. The total number and percentage of items assigned to each team is displayed at the bottom of the screen, as well as the total number of remaining, unassigned items.

The inventory lead may change each inventory team's assigned items based on building, row, or item as needed, as well as assign any remaining items. The inventory lead achieves this by selecting or deselecting the checkboxes for a given row or building or the radio buttons for each individual item. 
$\leftarrow$ Assigning Inventory

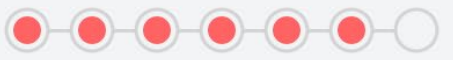

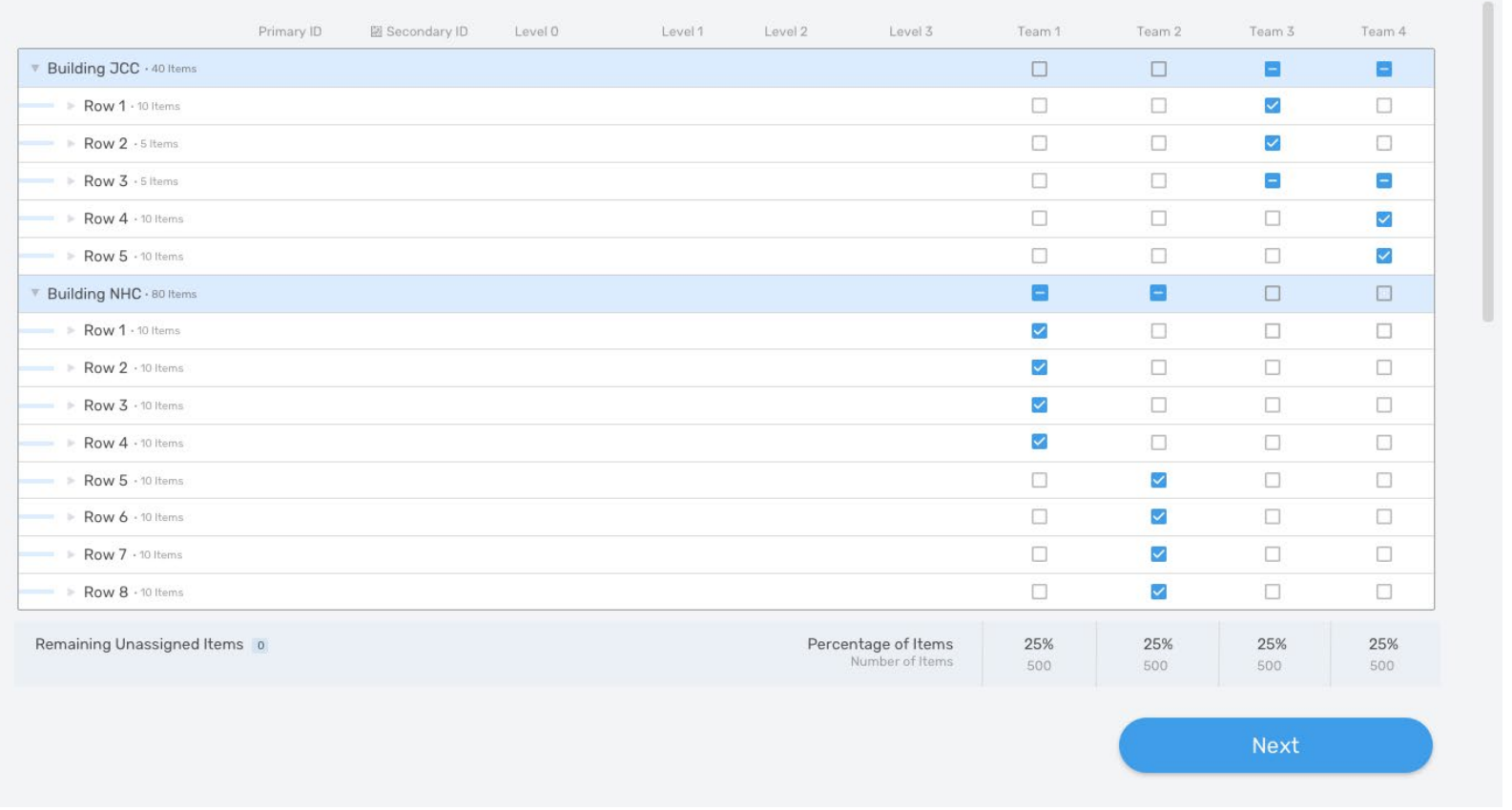

Figure 13. Inventory assignment, all rows collapsed. 


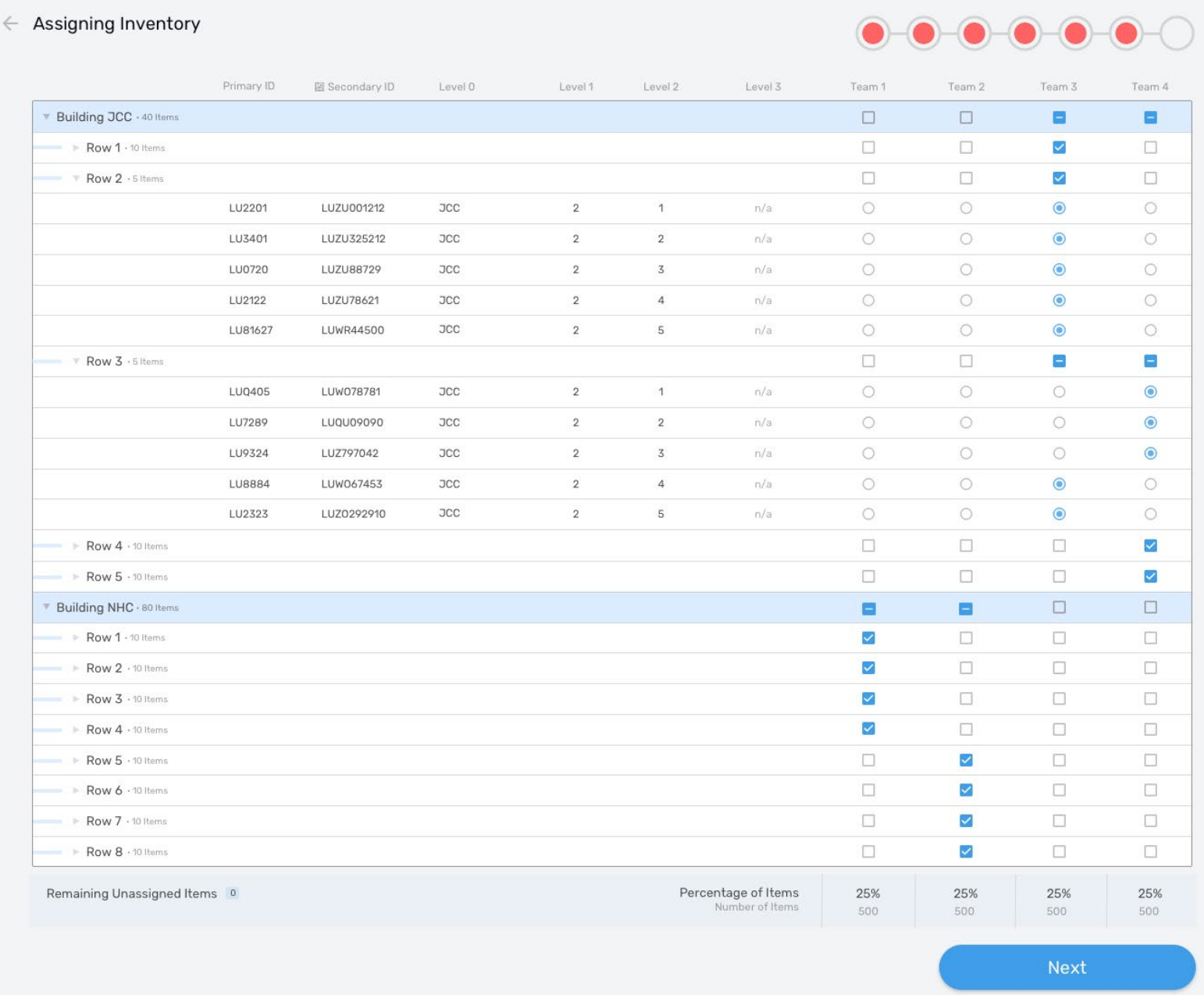

Figure 14. Inventory assignment, Rows 2 and 3 expanded.

On these screens, a checked checkbox indicates all subordinate items were assigned to that team, a dashed checkbox indicates that only some of the subordinate items were assigned to that team, and an open checkbox indicates none of the subordinate items were assigned to that team. Specific items use radio buttons to indicate they can only be assigned to a single team. In Figure 13, all items in Building JCC Rows 1 and 2 were assigned to Team 3. Some of the items in Building JCC Row 3 were assigned to Team 3 and some to Team 4. After expanding Rows 2 and 3 in Figure 14, the individual assigned items are shown with a selected radio button. It is evident that the first three items in Row 3 are assigned to Team 4 , and the last two items in Row 3 were assigned to Team 3.

The lead may reassign individual items by selecting the radio button for the item in the intended team's column. The lead may reassign an entire row or building of items by selecting the building or row header box in the intended team's column. The percentage of items and number of items at the bottom of the screen will update as items are re-assigned. The inventory lead is unable to distribute the assigned inventory lists to teams until all items are assigned, as tracked at the bottom left-hand portion of the screen. 


\subsection{DISTRIBUTE ASSIGNED INVENTORY LIST}

After all items have been assigned to the inventory teams, the inventory lead proceeds to upload the assigned inventory lists to the datastore where the teams subsequently download it to each mobile device. Figure 15 displays the inspector and device information for each inventory team and the progress for the mobile devices.
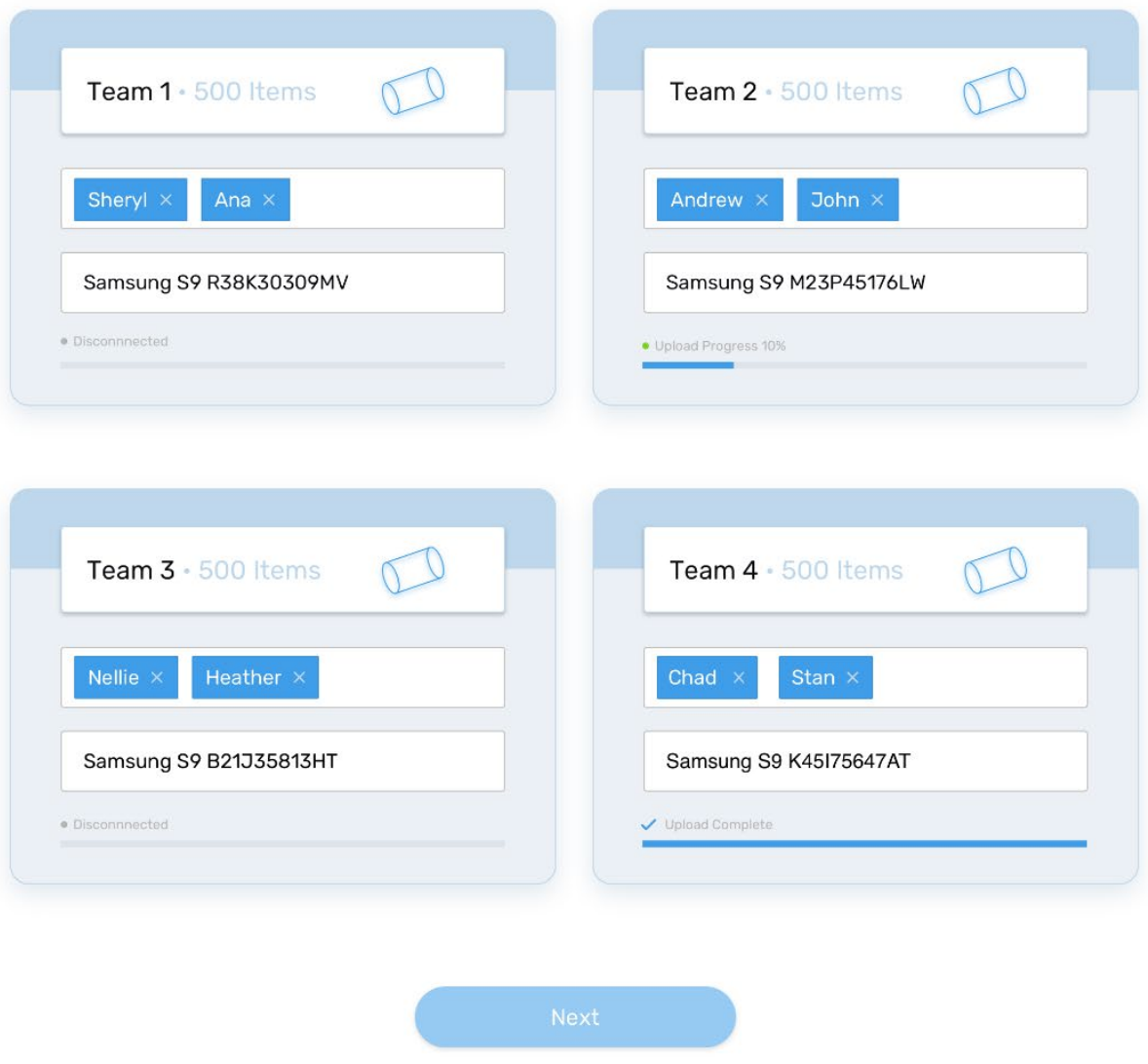

Figure 15. Upload assigned inventory list to each team's mobile device.

The full inventory list is uploaded to each mobile device, but the items assigned to other teams are "grayed out" and located underneath an inventory team's assigned inventory list. Although the entire operator-provided inventory list is searchable by all inventory teams, observations are not synchronized across devices in real time. The integration and reconciliation process accommodates the possibility that multiple teams may enter observations about the same item identification number, but these multiple observations will not be identified until the integration process by the inventory lead. 


\subsection{FIELD OBSERVATION ACTIVITIES IN PROGRESS}

While the inventory teams are conducting their field observation activities, DIRA displays a progress page that shows the site of the inventory activity (e.g., Oak Ridge National Laboratory), the number of registered mobile devices, and tracks the synchronization status of the assigned inventory and the observations log for each team (Figure 16). For the status of the assigned inventory lists for each team, Figure 16 shows that Team 1 has not connected its mobile device to download its assigned inventory list, and Team 2 completed its download but is still connected to the mobile dock. Additionally, Teams 3 and 4 successfully downloaded their assigned inventory lists, disconnected their devices, and conducted their inventory activities in the field. Team 3 is currently connected to the mobile dock to upload its observations log, and Team 4 uploaded its observations log and disconnected its mobile device.

At any time, the inventory lead can click Next to review the Needs Action, Acknowledged, and Completed items. Before any teams synchronize their observations log, every item on the inventory list will initially appear in the Needs Action category. As teams synchronize their observation logs, items will automatically be recategorized as described in Section 5.3.3.

Inventory leads are expected to remain on the screen shown in Figure 16 until several or all of the teams have synchronized their observations logs (e.g., before lunch or at the end of the day). The observations logs uploaded to the office computer are not automatically cleared from the mobile devices because an inventory inspection may occur over multiple days.

\section{Inventory App}

Inventory: Oak Ridge National Laboratory (2/21/19)

Assigned Inventory Status

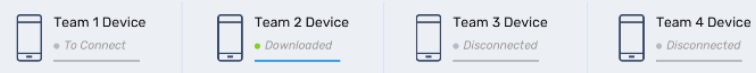

Observations Log Status

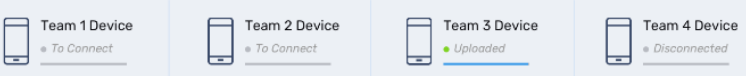

Figure 16. In-field observation activities in progress. 


\subsection{MAIN INTEGRATION PAGE}

The main page that displays the observations logs integrated with the inventory list is shown in Figure 17. All items are collapsed to display one row per item. Items that are observed in the field and/or are on the operator-provided inventory list are divided and displayed in three main categories:

- Needs Action

- Acknowledged

- Completed

As previously mentioned, all items are initially divided between the Needs Action or Completed categories, but the Acknowledged category remains empty. The total number of items in each category is displayed to the right of the header. As seen in Figure 17, after the initial integration of the Oak Ridge National Laboratory example inventory, 12 items Need Action by the inventory lead, 0 items are Acknowledged, and 1,989 items are considered Completed. The following information is presented for each item:

- Primary identification number (e.g., serial number for $U_{6}$ cylinders ${ }^{10}$ )

- Secondary identification number (e.g., Global ID for $\mathrm{UF}_{6}$ cylinders)

- Location by level 0 , level 1 , level 2, and level 3 hierarchy

- Inventory team assignment

- Composite observation timestamp

- Composite observation

- Comment icon (optional, hover capability)

- Reconciliation status

- Reconciliation status button (optional, may be enabled or disabled)

By default, items are sorted by the composite observation timestamp in each category (Needs Action, Acknowledged, or Completed). All items within a given category may be sorted by selecting the desired column header. Items may be also viewed by team or by building by selecting the buttons underneath the site location at the top of the screen.

${ }^{10}$ For new cylinders the serial number will likely be the same as the global identification number. 
View All View by Team View by Building

Needs Action 12

\begin{tabular}{|c|c|c|c|c|c|c|c|c|c|c|c|c|}
\hline fimary ID & Ea Secondary ID & Level 0 & Level1 & Level 2 & Level 3 & Team & Date $\mathbf{A}$ & Observation & & Status & & \\
\hline WNTA844640 & LUZU11564 & NHC & 5 & 40 & $n / a$ & 2 & & Not Observed & & $\mathbf{A}$ & 2 & Resolve \\
\hline WNTA762169 & & NHC & 1 & 8 & $n / a$ & 1 & & Not Observed & & $\mathbf{A}$ & 2 & Resolve \\
\hline WNTA762196 & & NHC & 1 & 8 & $n / a$ & 1 & $2019-02-2109: 49: 38$ & Added to List & 国 & $\mathbf{A}$ & 2 & Resolve \\
\hline YTUL002621 & & NHC & 6 & 37 & $n / a$ & 2 & $2019-02-2109: 47: 48$ & Duplicate - Within Team & 国 & $\mathbf{A}$ & $v^{2}$ & Resolve \\
\hline KYTL150695 & & NHC & 6 & 38 & $n / a$ & 2 & & Not Observed & & $\mathbf{A}$ & ${ }^{2}$ & Resolve \\
\hline WNTA56431 & LUZU001220 & NHC & 1 & 7 & $n / a$ & 1 & 2019-02-21 09:47:24 & observed & & 慗 & 2 & Acknowledge \\
\hline RHJK343168 & LUZU001207 & NHC & 8 & 1 & $n / a$ & 2 & 2019-02-21 09:40:20 & Observed & 国 & 慗 & v & Acknowledge \\
\hline URE762163 & LUZU001234 & NHC & 2 & 2 & n/a & 1 & 2019-02-21 09:37:50 & Duplicate - Multiple Teams & & $\mathbf{A}$ & ${ }^{2}$ & Resolve \\
\hline KJTU34561 & LUZU001252 & NHC & 3 & 3 & $n / a$ & 1 & $2019-02-2109: 36: 32$ & Duplicate - Within Team & & $\mathbf{A}$ & 2 & Resolve \\
\hline RHJK73924 & LUZU001222 & NHC & 4 & 6 & $n / a$ & 1 & 2019-02-21 09:35:34 & Added to List & 国 & $\boldsymbol{A}$ & 2 & Resolve \\
\hline MRU72246 & LUZU001200 & $\mathrm{NHC}$ & 6 & 5 & $n / a$ & 2 & 2019-02-21 09:35:23 & Observed & & 管 & ${ }^{2}$ & Acknowledge \\
\hline WNTA74839 & LUZU001215 & NHC & 5 & 10 & $n / a$ & 2 & & Not Observed & & $\mathbf{A}$ & ${ }^{2}$ & Resolve \\
\hline
\end{tabular}

Acknowledged 0

\begin{tabular}{|c|c|c|c|c|c|c|c|c|c|c|c|}
\hline Primary ID & Elal Secondary ID & Level 0 & Level1 & Level 2 & Level 3 & Team & Date * & observation & & Status & \\
\hline \multicolumn{12}{|c|}{ Completed 1.989} \\
\hline Primary ID & W Secondary ID & Level 0 & Level 1 & Level 2 & Level 3 & Team & Date - & observation & & Status & \\
\hline WNTA762170 & LUZU001212 & $\mathrm{NHC}$ & 1 & 1 & $\mathrm{n} / \mathrm{a}$ & 1 & 2019-02-21 09:45:19 & Observed & 曰 & () & $v$ \\
\hline KYTL123456 & & $\mathrm{NHC}$ & 1 & 2 & $n / a$ & 1 & 2019-02-21 09:43:13 & Observed & & () & $v$ \\
\hline YNTR541569 & LUZU21882 & NHC & 1 & 3 & $\mathrm{n} / \mathrm{a}$ & 1 & $2019-02-2109: 42: 42$ & Observed & & () & $\checkmark$ \\
\hline RHJK172690 & LUWR33246 & $\mathrm{NHC}$ & 1 & 4 & $\mathrm{n} / \mathrm{a}$ & 1 & $2019-03-3109: 34: 28$ & Observed & & () & $v$ \\
\hline WNTA762168 & LUZU09090 & $\mathrm{NHC}$ & 5 & 1 & $\mathrm{n} / \mathrm{a}$ & 2 & 2019-02-21 09:33:15 & Observed & & () & $v$ \\
\hline YHGL733639 & & NHC & 5 & 2 & $n / a$ & 2 & 2019-02-21 09:32:14 & Observed & & (2) & $v$ \\
\hline DULA340931 & LUZU28190 & $\mathrm{NHC}$ & 5 & 3 & $\mathrm{n} / \mathrm{a}$ & 2 & $2019-02-2109: 32: 00$ & Observed & & () & $\checkmark$ \\
\hline
\end{tabular}

Figure 17. Main integration page before reconciliation activities. 
The individual field observations are displayed in the expanded view by selecting the expand triangle on the right side of an item's header row. In Figure 18, the inventory lead expands item YTUL002621 in the Needs Action category, which displays the two observations recorded on the IFOA (e.g., "Duplicate Within Team" and Observed). These observations are displayed in chronological order and contain the following information:

- Observation timestamp recorded on IFOA

- Observation recorded on IFOA

- Comment icon (optional, hover capability)

\begin{tabular}{|c|c|c|c|c|c|c|c|c|c|c|c|c|}
\hline \multicolumn{13}{|c|}{8 Inventory App } \\
\hline \multicolumn{9}{|c|}{ Inventory: Oak Ridge National Laboratory (2/21/19) } & & & 0 & \multirow[t]{2}{*}{ Generate Report 【 } \\
\hline View All & View by Team & View by $\mathrm{B}$ & Iding & & & & & & & & & \\
\hline \multicolumn{13}{|c|}{ Needs Action 12} \\
\hline Primary ID & Eal Secondary ID & Levelo & Level1 & Level2 & Level3 & Team & Date - & observation & & status & & \\
\hline WNTAB44640 & LUZU11564 & $\mathrm{NHC}$ & 5 & 40 & $n / a$ & 2 & & Not Observed & & $\Delta$ & $\checkmark$ & Resolve \\
\hline WNTA762169 & & $\mathrm{NHC}$ & 1 & 8 & n/a & 1 & & Not Observed & & $\mathbf{A}$ & $\checkmark$ & Resolve \\
\hline WNTA762196 & & $\mathrm{NHC}$ & 1 & 8 & n/a & 1 & 2019-02-2109:49:38 & Added to List & 国 & $\Delta$ & 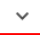 & Resolve \\
\hline \multirow[t]{3}{*}{ YTuL002621 } & & $\mathrm{NHC}$ & 6 & 37 & $\mathrm{n} / \mathrm{a}$ & 2 & 2019-02-21 09:47:48 & Duplicate - Within Team & 曰 & $\Delta$ & v & Resolve \\
\hline & & & & & & & $2019-02-2109: 47: 48$ & Duplicate - Within Team & 曰 & & & \\
\hline & & & & & & & 2019-02-21 09:46:23 & Observed & & & & \\
\hline KYTL150695 & & NHC & 6 & 38 & $n / a$ & 2 & & Not Observed & & $\mathbf{A}$ & $\checkmark$ & Resolve \\
\hline WNTA56431 & LUZU001220 & $\mathrm{NHC}$ & 1 & 7 & $\mathrm{n} / \mathrm{a}$ & 1 & 2019-02-21 09:47:24 & observed & & 管 & $\checkmark$ & Acknowledge \\
\hline RHJK73924 & LUZU001207 & $\mathrm{NHC}$ & 8 & 1 & n/a & 2 & 2019-02-21 09:40:20 & observed & 曰 & 龄 & v & Acknowledge \\
\hline MRU72246 & LUZU001234 & NHC & 2 & 2 & $\mathrm{n} / \mathrm{a}$ & 1 & 2019-02-21 09:37:50 & Duplicate - Multiple Teams & & $\mathbf{A}$ & $\checkmark$ & Resolve \\
\hline WNTA74839 & Luzuoo1252 & $\mathrm{NHC}$ & 3 & 3 & $n / a$ & 1 & 2019-02-21 09:36:32 & Duplicate - Within Team & & $\mathbf{A}$ & $\checkmark$ & Resolve \\
\hline RHJK73924 & LUZU001222 & $\mathrm{NHC}$ & 4 & 6 & $n / a$ & 1 & 2019-02-21 09:35:34 & Added to List & 目 & $\Delta$ & $\checkmark$ & Resolve \\
\hline MRU72246 & LUZU001200 & NHC & 6 & 5 & $n / a$ & 2 & 2019-02-21 09:35:23 & observed & & 慗 & $\checkmark$ & Acknowledge \\
\hline WNTA74839 & Luzuoo1215 & $\mathrm{NHC}$ & 5 & 10 & $\mathrm{n} / \mathrm{a}$ & 2 & & Not Observed & & $\mathbf{\Delta}$ & $\checkmark$ & Resolve \\
\hline \multicolumn{13}{|c|}{ Acknowledged 0} \\
\hline Primary ID & 国 Secondary 10 & Levelo & Level1 & Level2 & Level3 & Team & Date - & observation & & Status & & \\
\hline \multicolumn{13}{|c|}{ Completed 1.989} \\
\hline Primary ID & 낸 Secondary 1D & Levelo & Level1 & Level2 & Level3 & Team & Date - & observation & & Status & & \\
\hline WNTA762170 & LUZU001212 & $\mathrm{NHC}$ & 1 & 1 & $n / a$ & 1 & 2019-02-21 09:45:19 & Observed & 曰 & () & $\checkmark$ & \\
\hline KYTL123456 & & NHC & 1 & 2 & n/a & 1 & 2019-02-21 09:43:13 & Observed & & () & $\checkmark$ & \\
\hline YNTR541569 & LUZU21882 & $\mathrm{NHC}$ & 1 & 3 & $n / a$ & 1 & 2019-02-21 09:42:42 & observed & & () & $\checkmark$ & \\
\hline RHJK172690 & LUWR33246 & $\mathrm{NHC}$ & 1 & 4 & $n / a$ & 1 & 2019-03-31 09:34:28 & observed & & () & $\checkmark$ & \\
\hline WNTA762168 & LUzU09090 & $\mathrm{NHC}$ & 5 & 1 & n/a & 2 & 2019-02-21 09:33:15 & observed & & () & $\checkmark$ & \\
\hline YHGL733639 & & $\mathrm{NHC}$ & 5 & 2 & $n / a$ & 2 & 2019-02-21 09:32:14 & observed & & () & $\checkmark$ & \\
\hline DULA340931 & LUZU28190 & $\mathrm{NHC}$ & 5 & 3 & $n / a$ & 2 & 2019-02-21 09:32:00 & Observed & & () & $\checkmark$ & \\
\hline
\end{tabular}

Figure 18. Expanded item YTUL002621. 
If an observation recorded on the IFOA contains a comment from the inventory team, the comment icon will appear on both the expanded observation row as well as the item's header row. If an item contains more than one observation with more than one comment, then the most recent comment will be displayed on the header row. To display a full comment associated with an item, the inventory lead hovers the pointer over the comment icon (Figure 19).

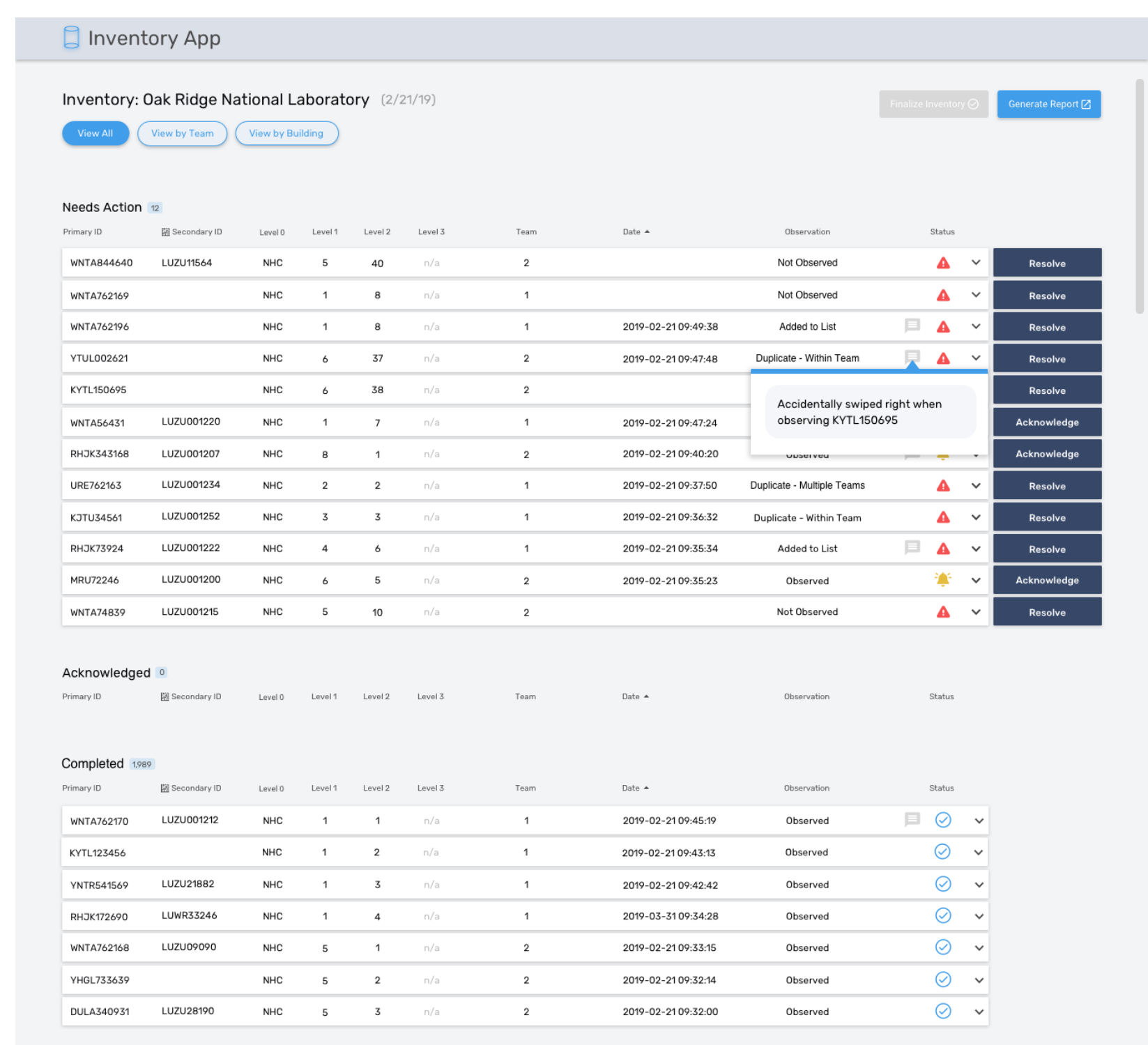

Figure 19. Displayed comment for item YTUL002621. 


\subsection{NO ACTION REQUIRED FOR ITEM WNTA762170}

As discussed in Section 5.5.1, items that are observed by the assigned team will appear in the Completed category and do not require any further action by the inventory lead. As shown in Figure 20, item WNTA762170 was observed once in the field by its assigned team, Team 1. Note, the inventory team entered a comment and the reconciliation status is "information" as indicated by the comment icon and blue checkmark. Inventory teams have the option to add comments even if an item is observed once in the field.

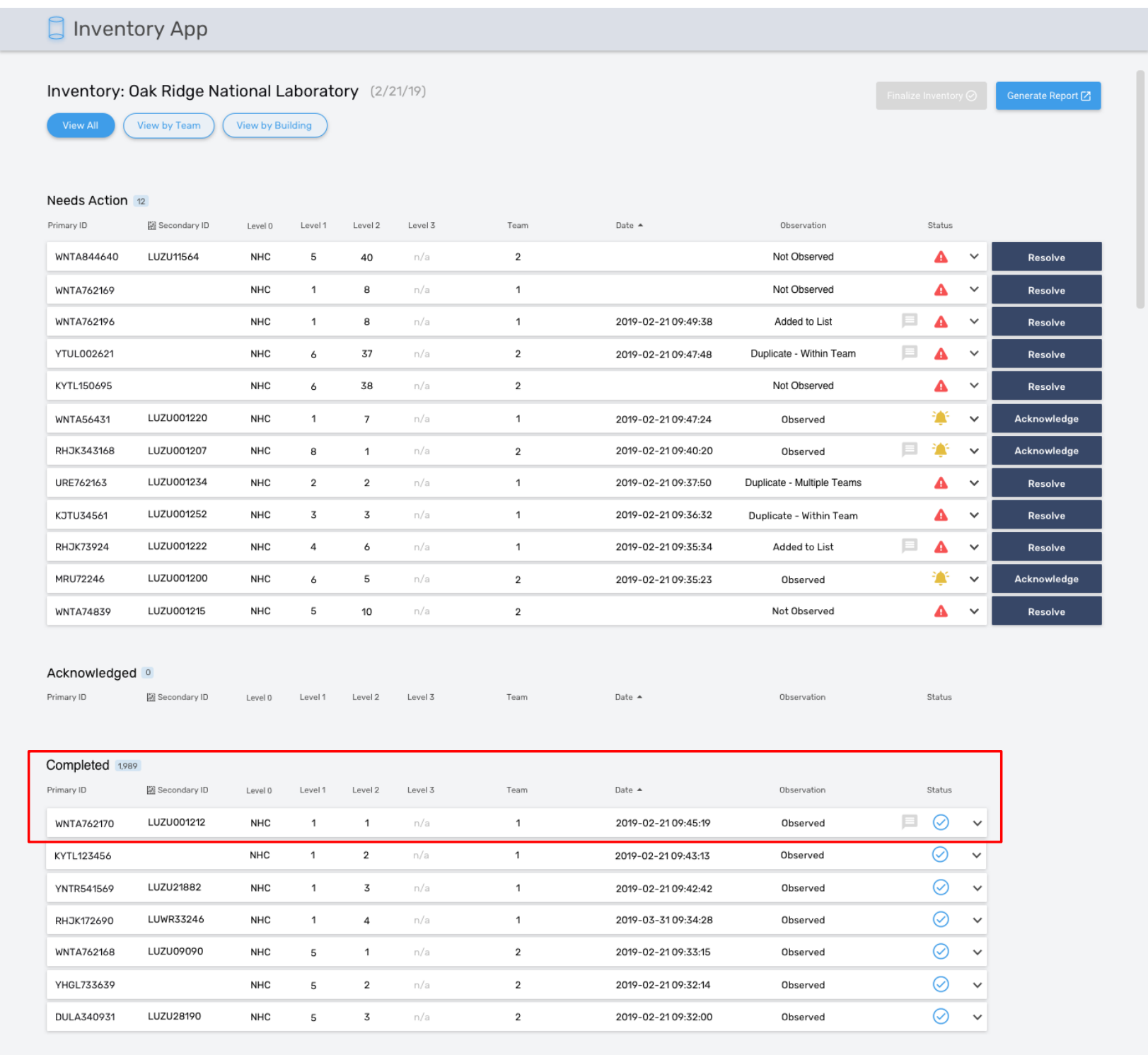

Figure 20. Items like WNTA762170 require no action from the inventory lead. 


\subsection{ACKNOWLEDGE A WARNING FOR ITEM WNTA56431}

As discussed in Section 5.5.2, items with a warning reconciliation status appear in the Needs Action category. In Figure 21, item WNTA56431 has a warning status icon and an enabled Acknowledge button to the right of the item's row. To acknowledge the warning, the inventory lead may expand (not shown) item WNTA56431's observations on the main integration page and discuss with the inventory team. Once satisfied, the inventory lead selects the Acknowledge button, which moves item WNTA56431 from the Needs Action to the Acknowledged category on the main integration page and grays out the item's reconciliation status (Figure 22). The composite observation does not change.

\begin{tabular}{|c|c|c|c|c|c|c|c|c|c|c|c|c|}
\hline \multicolumn{13}{|c|}{ B Inventory App } \\
\hline \multicolumn{9}{|c|}{ Inventory: Oak Ridge National Laboratory (2/21/19) } & \multicolumn{3}{|c|}{ Finalize linuentory $\bigcirc$} & Generate Report【 \\
\hline \multicolumn{13}{|c|}{ Needs Action 12} \\
\hline Primary ID & E) Secondary ID & Level 0 & Level1 & Level 2 & Level 3 & Team & Date - & Observation & & status & & \\
\hline WNTA844640 & LUZU11564 & $\mathrm{NHC}$ & 5 & 40 & $n / a$ & 2 & & Not Observed & & $\mathbf{A}$ & $\checkmark$ & Resolve \\
\hline WNTA762169 & & $\mathrm{NHC}$ & 1 & 8 & $n / a$ & 1 & & Not Observed & & $\boldsymbol{A}$ & $\checkmark$ & Resolve \\
\hline WNTA762196 & & $\mathrm{NHC}$ & 1 & 8 & $n / a$ & 1 & $2019-02-2109: 49: 38$ & Added to List & 回 & $\mathbf{A}$ & $\checkmark$ & Resolve \\
\hline YTUL002621 & & $\mathrm{NHC}$ & 6 & 37 & $n / a$ & 2 & $2019-02-2109: 47: 48$ & Duplicate - Within Team & 国 & $\mathbf{A}$ & $\checkmark$ & Resolve \\
\hline KYTL150695 & & $\mathrm{NHC}$ & 6 & 38 & $n / a$ & 2 & & Not Observed & & $\Delta$ & $\checkmark$ & Resolve \\
\hline WNTA56431 & LUZU001220 & $\mathrm{NHC}$ & 1 & 7 & $n / a$ & 1 & $2019-02-2109: 47: 24$ & observed & & 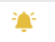 & $\checkmark$ & Acknowledge \\
\hline RHJK343168 & LUZU001207 & $\mathrm{NHC}$ & 8 & 1 & $n / a$ & 2 & $2019-02-2109: 40: 20$ & observed & 国 & 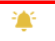 & $v$ & Acknowledge \\
\hline URE762163 & LUZU001234 & $\mathrm{NHC}$ & 2 & 2 & $n / a$ & 1 & $2019-02-21$ 09:37:50 & Duplicate - Multiple Teams & & $\mathbf{A}$ & $\checkmark$ & Resolve \\
\hline КЈTU34561 & LUZU001252 & $\mathrm{NHC}$ & 3 & 3 & $n / a$ & 1 & $2019-02-2109: 36: 32$ & Duplicate - Within Team & & $\mathbf{A}$ & $\checkmark$ & Resolve \\
\hline RHJK73924 & LUZU001222 & $\mathrm{NHC}$ & 4 & 6 & $n / a$ & 1 & $2019-02-2109: 35: 34$ & Added to List & 曰 & $\mathbf{A}$ & $\checkmark$ & Resolve \\
\hline MRU72246 & LUZuo01200 & $\mathrm{NHC}$ & 6 & 5 & $n / a$ & 2 & $2019-02-2109: 35: 23$ & observed & & 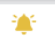 & $\checkmark$ & Acknowledge \\
\hline WNTA74839 & LUZU001215 & $\mathrm{NHC}$ & 5 & 10 & $n / a$ & 2 & & Not Observed & & $\mathbf{A}$ & $\checkmark$ & Resolve \\
\hline \multicolumn{13}{|c|}{ Acknowledged 0} \\
\hline Primary ID & 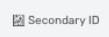 & Level 0 & Level1 & Level 2 & Level 3 & Team & Date - & observation & & Status & & \\
\hline \multicolumn{13}{|c|}{ Completed 1.989} \\
\hline Primary ID & [an Secondary ID & Level 0 & Level1 & Level 2 & Level3 & Team & Date - & observation & & status & & \\
\hline WNTA762170 & LUZU001212 & $\mathrm{NHC}$ & 1 & 1 & $n / a$ & 1 & $2019-02-2109: 45: 19$ & observed & 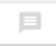 & ( ) & $\checkmark$ & \\
\hline KYTL123456 & & $\mathrm{NHC}$ & 1 & 2 & $n / a$ & 1 & $2019-02-2109: 43: 13$ & observed & & ○ & $\checkmark$ & \\
\hline YNTR541569 & LUZU21882 & $\mathrm{NHC}$ & 1 & 3 & $n / a$ & 1 & $2019-02-21$ 09:42:42 & Observed & & ( & $\checkmark$ & \\
\hline RHJK172690 & LUWR33246 & $\mathrm{NHC}$ & 1 & 4 & $n / a$ & 1 & $2019-03-3109: 34: 28$ & Observed & & $\ominus$ & $\checkmark$ & \\
\hline WNTA762168 & LUZU09090 & $\mathrm{NHC}$ & 5 & 1 & $n / a$ & 2 & 2019-02-21 09:33:15 & Observed & & () & $\checkmark$ & \\
\hline YHGL733639 & & $\mathrm{NHC}$ & 5 & 2 & $n / a$ & 2 & $2019-02-2109: 32: 14$ & observed & & () & $\checkmark$ & \\
\hline DULA340931 & LUZU28190 & $\mathrm{NHC}$ & 5 & 3 & $n / a$ & 2 & $2019-02-2109: 32: 00$ & observed & & ( & $\checkmark$ & \\
\hline
\end{tabular}

Figure 21. Item WNTA56431 has a warning reconciliation status and needs action by the inventory lead. 


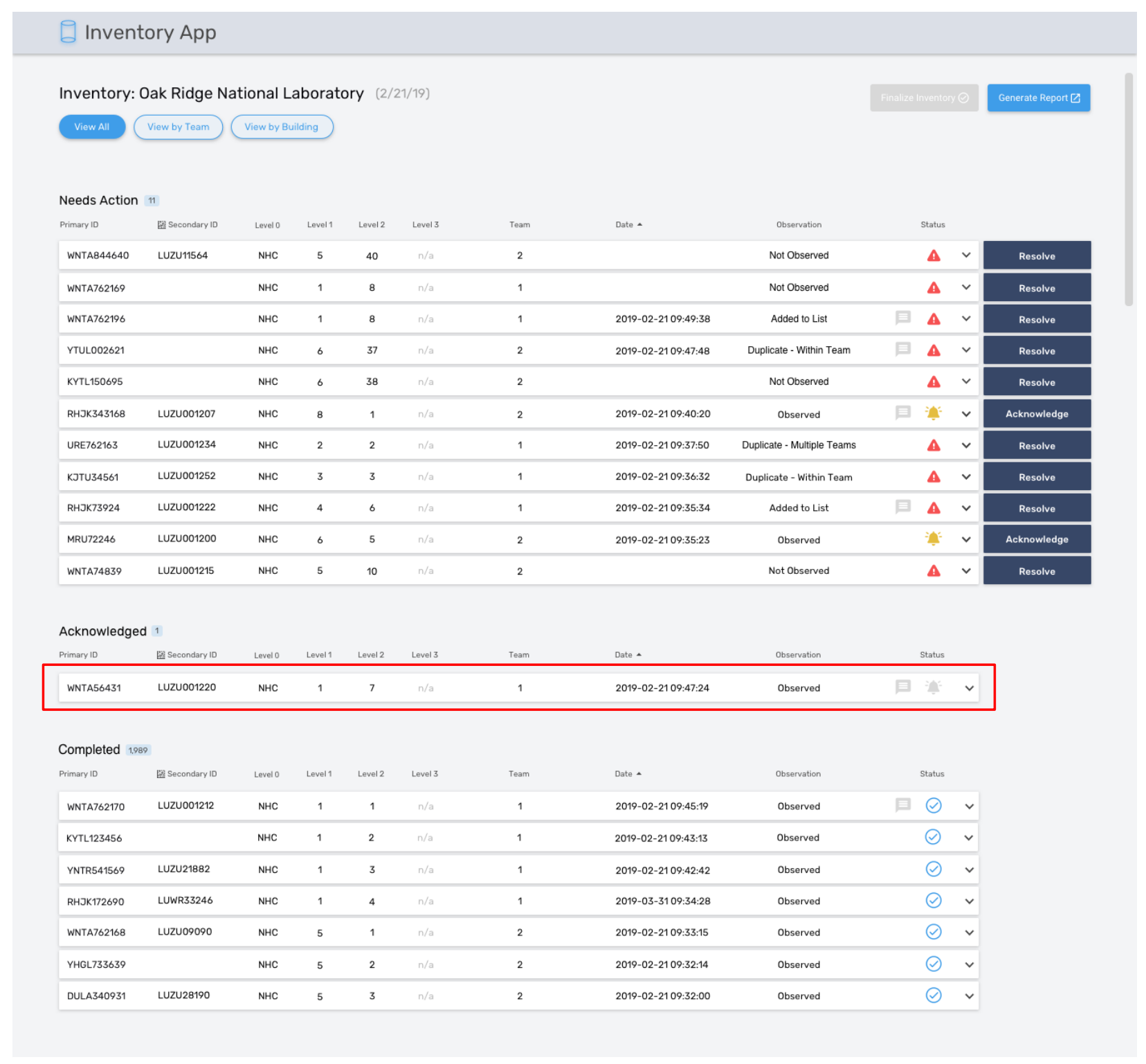

Figure 22. The warning for item WNTA56431 is acknowledged by the inventory lead. Composite observation does not change, and the reconciliation status is grayed out. 


\subsection{ACKNOWLEDGE AN ERROR FOR ITEM WNTA844640}

As discussed in Section 5.5.3, items with an error reconciliation status appear in the Needs Action category. For this section, item WNTA 844640 will be examined. This item has a composite observation of "Not Observed" and can be described by scenario 4 in Table 4. In Figure 23, item WNTA844640 has an error status icon and an enabled Resolve button to the right of the item's row. The inventory lead selects the "Resolve" button to navigate to a separate reconciliation page.

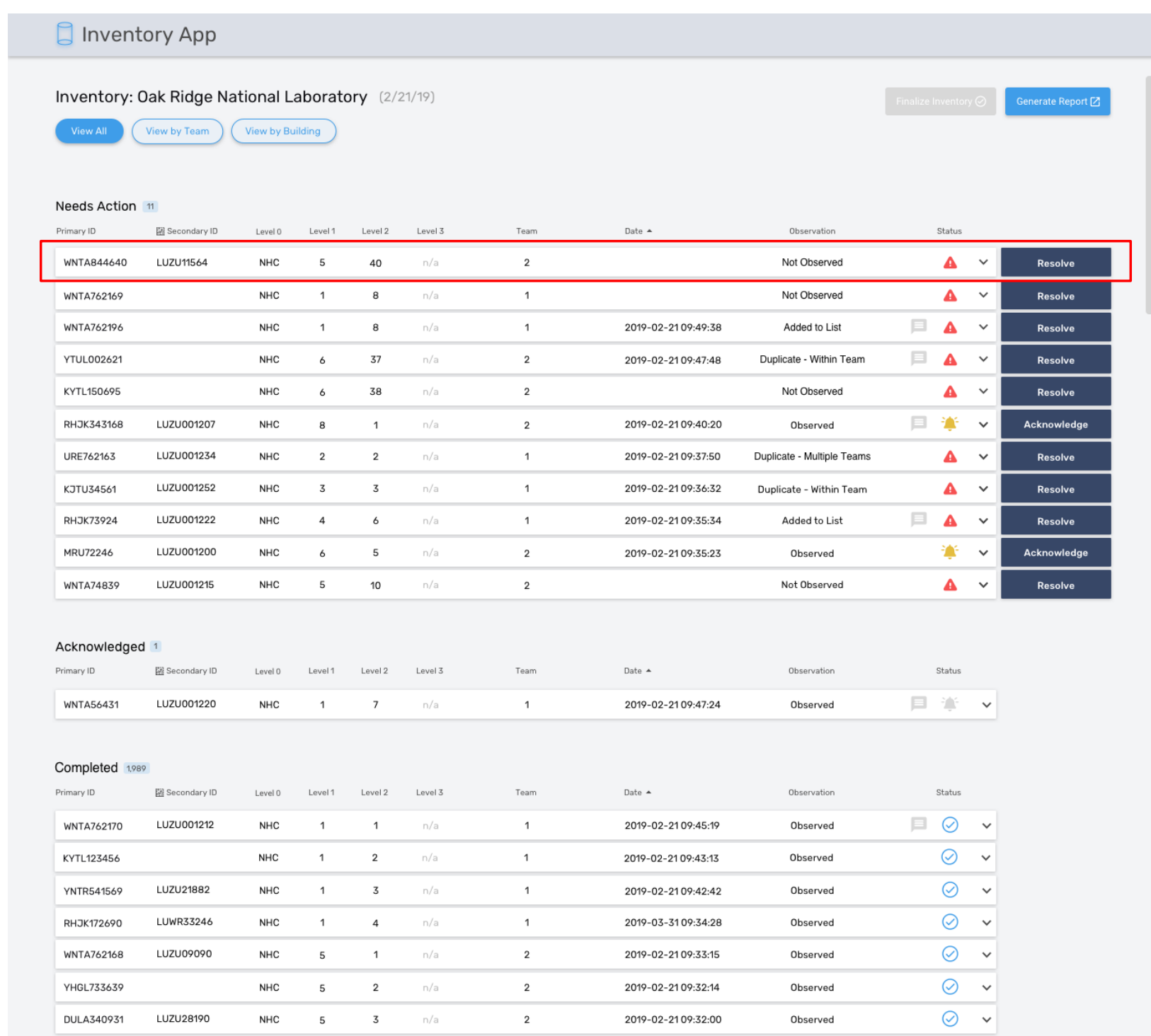

Figure 23. Item WNTA844640 (Not Observed) has an error reconciliation status and needs action by the inventory lead. 
The reconciliation page for item WNTA844640 is shown in Figure 24. All information for the item is automatically expanded and displayed at the top of the page. A checkbox is located to the right of the item selected for reconciliation. Directly below the selected item is a section titled Needs Action. All items with an error reconciliation status are collapsed and displayed as one row per item. ${ }^{11}$ Similar to the main integration page, items in this section may be expanded, collapsed, or sorted by selecting the desired column header. Additionally, the inventory lead may read any comments by hovering over the comment icon. Checkboxes are located to the right of each item.

Inventory App

\begin{tabular}{|c|c|c|c|c|c|c|c|c|c|c|c|c|}
\hline Primary ID & Gecondary 10 & Level0 & Level1 & Level 2 & Level 3 & Team & Date - & observation & & Status & & Select \\
\hline WNTA844640 & LUZU11564 & $\mathrm{NHC}$ & 5 & 40 & $n / a$ & 2 & & Not Observed & & $\boldsymbol{A}$ & v & $\checkmark$ \\
\hline \multicolumn{13}{|c|}{ Needs Action 8} \\
\hline Primary ID & Secondary ID & Level 0 & Level1 & Level 2 & Level 3 & Team & Date . & Observation & & Status & & Select \\
\hline WNTA762169 & & $\mathrm{NHC}$ & 1 & 8 & $n / a$ & 1 & & Not Observed & & $\boldsymbol{A}$ & $v^{2}$ & $\square$ \\
\hline WNTA762196 & & $\mathrm{NHC}$ & 1 & 8 & $n / a$ & 1 & $2019-02-2109: 49: 38$ & Added to List & 目 & $\boldsymbol{A}$ & $v^{2}$ & $\square$ \\
\hline YTUL002621 & & $\mathrm{NHC}$ & 6 & 37 & $n / a$ & 2 & $2019-02-2109: 47: 48$ & Duplicate - Within Team & 国 & $\boldsymbol{A}$ & 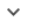 & $\square$ \\
\hline KYTL150695 & & $\mathrm{NHC}$ & 6 & 38 & $n / a$ & 2 & & Not Observed & & $\boldsymbol{A}$ & v & $\square$ \\
\hline URE762163 & LUZU001234 & $\mathrm{NHC}$ & 2 & 2 & $n / a$ & 1 & 2019-02-21 09:37:50 & Duplicate - Multiple Teams & & $\mathbf{A}$ & $\checkmark$ & $\square$ \\
\hline КכTU34561 & LUZU001252 & $\mathrm{NHC}$ & 3 & 3 & $n / a$ & 1 & $2019-02-2109: 36: 32$ & Duplicate - Within Team & & $\boldsymbol{A}$ & v & $\square$ \\
\hline RHJK73924 & LUZU001222 & $\mathrm{NHC}$ & 4 & 6 & $n / a$ & 1 & $2019-02-2109: 35: 34$ & Added to List & 回 & $\mathbf{A}$ & v & $\square$ \\
\hline WNTA74839 & LUZU001215 & NHC & 5 & 10 & $n / a$ & 2 & & Not Observed & & $\mathbf{A}$ & 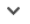 & $\square$ \\
\hline
\end{tabular}

- Resolve after merging observation(s) with items and adding a comment

- Acknowledge an item after adding a comment.

- Cancel to exit with no action.
Inventory Lead Comments Add a comment...

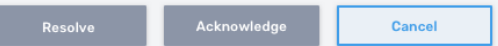

Figure 24. Initial reconciliation page for item WNTA844640 (Not Observed).

At the bottom of the page is a section for inventory lead comments and three buttons. The Resolve and Acknowledge buttons are initially disabled and the "Cancel" button is enabled. The inventory lead may select Cancel at any time to return to the main integration page.

\footnotetext{
${ }^{11}$ Items that have a warning or information reconciliation status are not displayed. Items that have been previously acknowledged or resolved by the inventory lead are not displayed.
} 
For this hypothetical example, the inventory lead spoke with the operator who said that the item was shipped off-site 6 months ago and was incorrectly left on the inventory list. Since there is no way to resolve (i.e., change the composite observation, of this item, the inventory lead must acknowledge the item by adding a comment describing the situation). This enables the Acknowledge button as seen in Figure 25 .

Inventory App

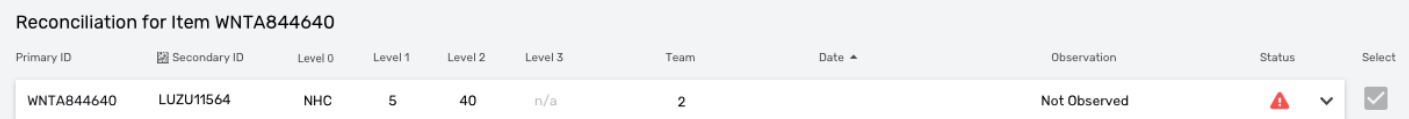

\begin{tabular}{|c|c|c|c|c|c|c|c|c|c|c|c|c|}
\hline Primary ID & 줄 Secondary 10 & Level 0 & Level1 & Level2 & Level 3 & Team & Date - & Observation & & Status & & Select \\
\hline WNTA762169 & & $\mathrm{NHC}$ & 1 & 8 & $\mathrm{n} / \mathrm{a}$ & 1 & & Not Observed & & $\mathbf{A}$ & 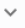 & $\square$ \\
\hline WNTA762196 & & $\mathrm{NHC}$ & 1 & 8 & $\mathrm{n} / \mathrm{a}$ & 1 & $2019-02-2109: 49: 38$ & Added to List & 回 & $\mathbf{A}$ & 2 & $\square$ \\
\hline YTUL002621 & & NHC & 6 & 37 & $\mathrm{n} / \mathrm{a}$ & 2 & $2019-02-2109: 47: 48$ & Duplicate - Within Team & 回 & $\mathbf{A}$ & 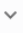 & $\square$ \\
\hline KYTL150695 & & $\mathrm{NHC}$ & 6 & 38 & $\mathrm{n} / \mathrm{a}$ & 2 & & Not Observed & & $\mathbf{A}$ & 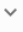 & $\square$ \\
\hline URE762163 & LUZU001234 & $\mathrm{NHC}$ & 2 & 2 & $n / a$ & 1 & $2019-02-2109: 37: 50$ & Duplicate - Multiple Teams & & $\mathbf{A}$ & 2 & $\square$ \\
\hline KJTU34561 & LUZU001252 & $\mathrm{NHC}$ & 3 & 3 & $n / a$ & 1 & $2019-02-2109: 36: 32$ & Duplicate - Within Team & & $\mathbf{A}$ & $\checkmark$ & $\square$ \\
\hline RHJK73924 & LUZU001222 & $\mathrm{NHC}$ & 4 & 6 & $n / a$ & 1 & $2019-02-2109: 35: 34$ & Added to List & 国 & $\Delta$ & 2 & $\square$ \\
\hline WNTA74839 & LUZU001215 & $\mathrm{NHC}$ & 5 & 10 & $n / a$ & 2 & & Not Observed & & $\mathbf{A}$ & $\checkmark$ & 口 \\
\hline
\end{tabular}

- Resolve after merging observation(s) with items and adding a comment

- Acknowledge an item after adding a comment.

- Cancel to exit with no action.
Inventory Lead Comments

Item not found in the field. Operator said item was shipped off-site on 2018-08-19. Item ID left on inventory list by accident.

Figure 25. Reconciliation page for item WNTA844640 (Not Observed) after inventory lead adds a comment. 
The inventory lead then selects the Acknowledge button which navigates them back to the main integration page. In Figure 26, item WNTA844640 is moved from the Needs Action to the Acknowledged category, its reconciliation status is grayed out, and the composite observation does not change.

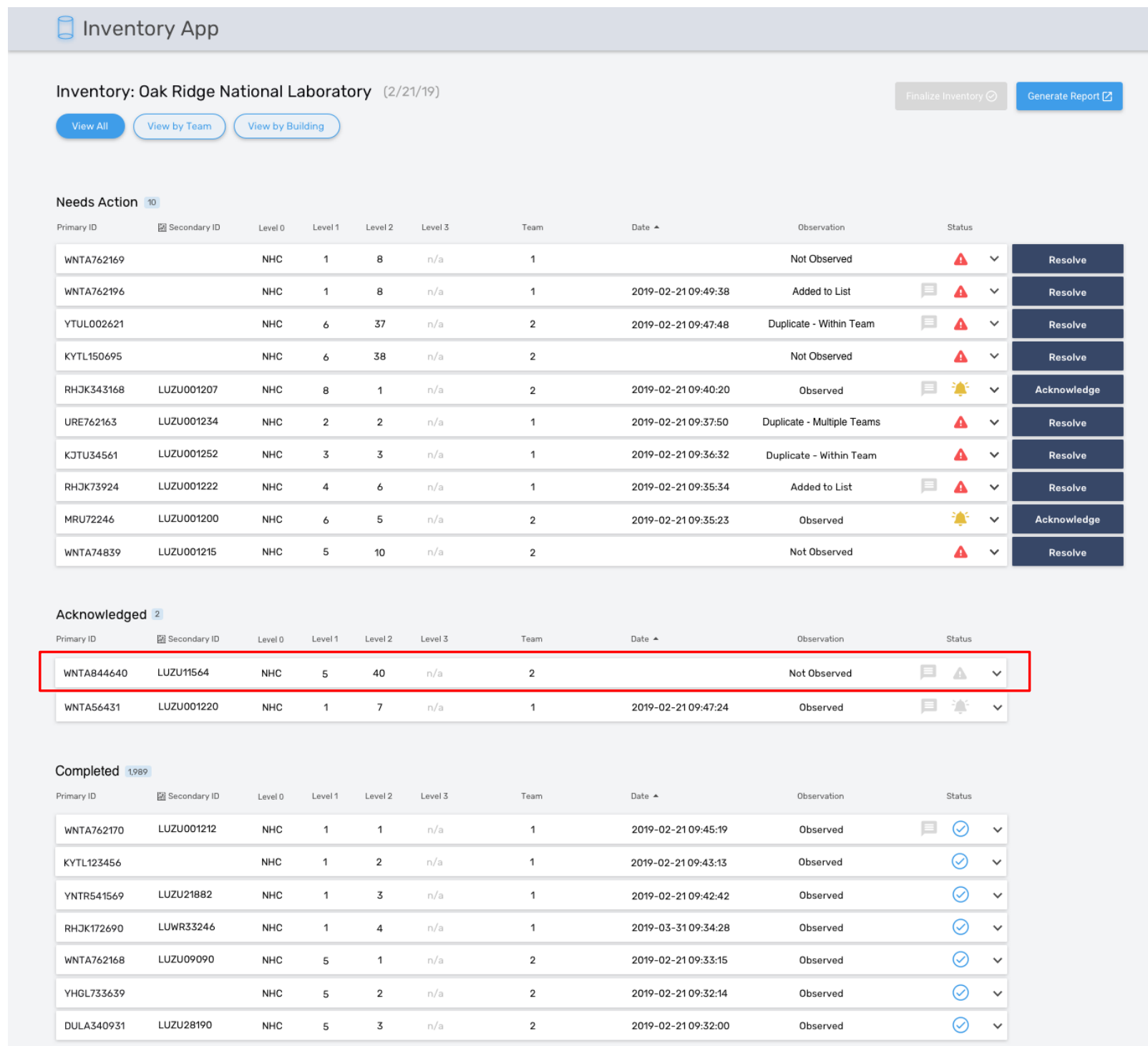

Figure 26. Item WNTA844640 (Not Observed) after the inventory lead acknowledges the error. Composite observation does not change, and the reconciliation status is grayed out. 


\subsection{RESOLVE AN ERROR-MERGE TWO ITEMS}

Scenario 10 in Table 4 and Table 8 describes when an inventory team typed the wrong identification number during manual search, then entered an observation about that incorrect identification number and added it to the inventory list. Subsequently, Team A did not record an observation for the intended item. This section details the resolution process for this example. In Figure 27, items WNTA762169 and WNTA762196 are listed in the Needs Action section. Item WNTA762169 has a composite observation of Not Observed and item WNTA762196 has a composite observation of "Added to List." Both items have an error status icon and an enabled Resolve button to the right of the item's row. The inventory lead selects the Resolve button for item WNTA762169 to navigate to a separate reconciliation page (Figure 28).

Inventory App

Inventory: Oak Ridge National Laboratory (2/21/19)

Generate Report巴

View All View by Team View by Building

Needs Action 10

\begin{tabular}{|c|c|c|c|c|c|c|c|c|c|c|c|c|}
\hline Primary ID & E. Secondary ID & Level 0 & Level1 & Level2 & Level 3 & Team & Date . & observation & & Status & & \\
\hline WNTA762169 & & $\mathrm{NHC}$ & 1 & 8 & $n / a$ & 1 & & Not Observed & & $\boldsymbol{A}$ & 2 & Resolve \\
\hline WNTA762196 & & $\mathrm{NHC}$ & 1 & 8 & $n / a$ & 1 & 2019-02-21 09:49:38 & Added to List & 国 & A & 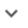 & Resolve \\
\hline YTUL002621 & & $\mathrm{NHC}$ & 6 & 37 & $n / a$ & 2 & $2019-02-2109: 47: 48$ & Duplicate - Within Team & 国 & $\mathbf{A}$ & 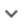 & Resolve \\
\hline KYTL150695 & & $\mathrm{NHC}$ & 6 & 38 & n/a & 2 & & Not Observed & & $\mathbf{A}$ & 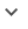 & Resolve \\
\hline RHJK343168 & LUZU001207 & $\mathrm{NHC}$ & 8 & 1 & $n / a$ & 2 & $2019-02-2109: 40: 20$ & Observed & 国 & 慗 & 2 & Acknowledge \\
\hline URE762163 & LUZU001234 & $\mathrm{NHC}$ & 2 & 2 & $n / a$ & 1 & 2019-02-21 09:37:50 & Duplicate - Multiple Teams & & $\mathbf{A}$ & v & Resolve \\
\hline KJTU34561 & LUZU001252 & $\mathrm{NHC}$ & 3 & 3 & $n / a$ & 1 & 2019-02-21 09:36:32 & Duplicate - Within Team & & $\mathbf{A}$ & 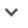 & Resolve \\
\hline RHJK73924 & LUZU001222 & $\mathrm{NHC}$ & 4 & 6 & $n / a$ & 1 & 2019-02-21 09:35:34 & Added to List & 国 & $\boldsymbol{A}$ & 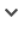 & Resolve \\
\hline MRU72246 & LUZU001200 & $\mathrm{NHC}$ & 6 & 5 & $n / a$ & 2 & 2019-02-21 09:35:23 & Observed & & 彎 & v & Acknowledge \\
\hline WNTA74839 & LUZU001215 & $\mathrm{NHC}$ & 5 & 10 & $n / a$ & 2 & & Not Observed & & $\boldsymbol{A}$ & v & Resolve \\
\hline
\end{tabular}

Acknowledged 2

\begin{tabular}{|c|c|c|c|c|c|c|c|c|c|c|c|}
\hline Primary ID & Q2] Secondary 10 & Level 0 & Level1 & Level 2 & Level 3 & Team & Date - & observation & & Status & \\
\hline WNTA844640 & LUZU11564 & $\mathrm{NHC}$ & 5 & 40 & $\mathrm{n} / \mathrm{a}$ & 2 & & Not Observed & 国 & $\Delta$ & $v$ \\
\hline WNTA56431 & LUZU001220 & $\mathrm{NHC}$ & 1 & 7 & $\mathrm{n} / \mathrm{a}$ & 1 & $2019-02-21$ 09:47:24 & Observed & 国 & 整 & $v$ \\
\hline
\end{tabular}

Completed 1989

\begin{tabular}{|c|c|c|c|c|c|c|c|c|c|c|c|}
\hline Primary ID & Wal Secondary ID & Level 0 & Level1 & Level 2 & Level 3 & Team & Date * & observation & & Status & \\
\hline WNTA762170 & LUZU001212 & $\mathrm{NHC}$ & 1 & 1 & n/a & 1 & $2019-02-2109: 45: 19$ & Observed & 国 & () & $v$ \\
\hline KYTL123456 & & $\mathrm{NHC}$ & 1 & 2 & $n / a$ & 1 & $2019-02-2109: 43: 13$ & Observed & & ( & $\checkmark$ \\
\hline YNTR541569 & LUZU21882 & $\mathrm{NHC}$ & 1 & 3 & $n / a$ & 1 & 2019-02-21 09:42:42 & Observed & & () & $v$ \\
\hline RHJK172690 & LUWR33246 & $\mathrm{NHC}$ & 1 & 4 & $\mathrm{n} / \mathrm{a}$ & 1 & $2019-03-3109: 34: 28$ & Observed & & ( & $\checkmark$ \\
\hline WNTA762168 & LUZU09090 & $\mathrm{NHC}$ & 5 & 1 & $n / a$ & 2 & 2019-02-21 09:33:15 & Observed & & $\ominus$ & $v$ \\
\hline YHGL733639 & & NHC & 5 & 2 & $n / a$ & 2 & $2019-02-2109: 32: 14$ & Observed & & () & $v$ \\
\hline DULA340931 & LUZU28190 & NHC & 5 & 3 & $n / a$ & 2 & $2019-02-2109: 32: 00$ & Observed & & () & $\checkmark$ \\
\hline
\end{tabular}

Figure 27. Items WNTA762169 (Not Observed) and WNTA762196 (Added to List) have an error reconciliation status and need action by the inventory lead. 


\begin{tabular}{|c|c|c|c|c|c|c|c|c|c|c|c|c|}
\hline Primary ID & Secondary 10 & Level 0 & Level1 & Level 2 & Level 3 & Team & Date . & observation & & Status & & Select \\
\hline WNTA762169 & & $\mathrm{NHC}$ & 1 & 8 & $n / a$ & 1 & & Not Observed & & $\mathbf{A}$ & v & $\checkmark$ \\
\hline \multicolumn{13}{|c|}{ Needs Action 7} \\
\hline Primary ID & 幽 Secondary 10 & Level 0 & Level1 & Level2 & Level3 & Team & Date - & observation & & Status & & Select \\
\hline WNTA762196 & & $\mathrm{NHC}$ & 1 & 8 & $n / a$ & 1 & 2019-02-21 09:49:38 & Added to List & 回 & $\mathbf{A}$ & $\checkmark$ & $\square$ \\
\hline YTUL002621 & & $\mathrm{NHC}$ & 6 & 37 & n/a & 2 & 2019-02-21 09:47:48 & Duplicate - Within Team & 回 & $\mathbf{A}$ & $\checkmark$ & $\square$ \\
\hline KYTL150695 & & $\mathrm{NHC}$ & 6 & 38 & $n / \mathrm{a}$ & 2 & & Not Observed & & $\mathbf{A}$ & v & $\square$ \\
\hline URE762163 & LUZU001234 & $\mathrm{NHC}$ & 2 & 2 & $n / a$ & 1 & 2019-02-21 09:37:50 & Duplicate - Multiple Teams & & $\mathbf{A}$ & 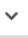 & $\square$ \\
\hline КЈTU34561 & LUZU001252 & $\mathrm{NHC}$ & 3 & 3 & $n / a$ & 1 & $2019-02-2109: 36: 32$ & Duplicate - Within Team & & $\mathbf{A}$ & v & $\square$ \\
\hline RHJK73924 & LUZU001222 & NHC & 4 & 6 & $\mathrm{n} / \mathrm{a}$ & 1 & $2019-02-2109: 35: 34$ & Added to List & 国 & $\mathbf{A}$ & $\checkmark$ & $\square$ \\
\hline WNTA74839 & LUZU001215 & $\mathrm{NHC}$ & 5 & 10 & $n / a$ & 2 & & Not Observed & & $\mathbf{A}$ & 2 & $\square$ \\
\hline
\end{tabular}

- Resolve after merging observation(s) with items and adding a comment

Inventory Lead Comments

- Acknowledge an item after adding a comment.

Add a comment...

- Cancel to exit with no action.

Figure 28. Initial reconciliation page for item WNTA762169 (Not Observed). 
In this hypothetical example, the inventory lead spoke with the operator who said item WNTA762169 is present on-site based on the facility records. The inventory lead begins to browse the Needs Action section by sorting items based on the composite observation. The inventory lead notes that item WNTA762196 has an Added to List composite observation and was added to the inventory list by the same team assigned to item WNTA762169. Additionally, the lead notices that both items are in the same location. By looking at the information for both items, speaking with the operator, and speaking with the inventory team, the lead determines the inventory team accidentally transposed the last two digits of the identification number when manually searching for item WNTA762169. The inventory lead selects the checkbox next to WTNA762196 (Figure 29).

Inventory App

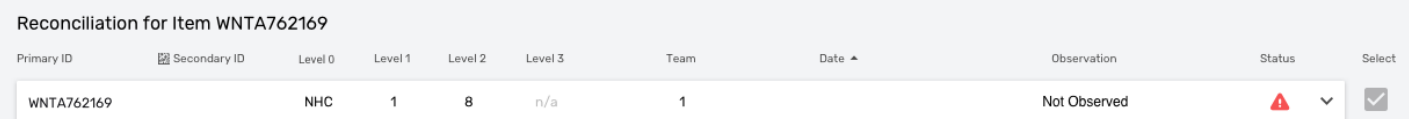

Needs Action 7

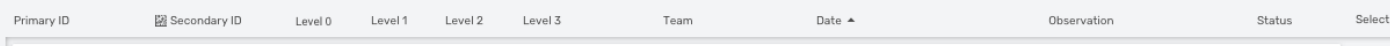

\begin{tabular}{|c|c|c|c|c|c|c|c|c|c|c|c|c|}
\hline WNTA762196 & & $\mathrm{NHC}$ & 1 & 8 & $n / a$ & 1 & 2019-02-21 09:49:38 & Added to List & 目 & $\mathbf{A}$ & $\checkmark$ & $\checkmark$ \\
\hline YTUL002621 & & $\mathrm{NHC}$ & 6 & 37 & $n / a$ & 2 & 2019-02-21 09:47:48 & Duplicate - Within Team & 曰 & $\mathbf{A}$ & $\checkmark$ & $\square$ \\
\hline KYTL150695 & & $\mathrm{NHC}$ & 6 & 38 & n/a & 2 & & Not Observed & & $\mathbf{A}$ & $v$ & $\square$ \\
\hline URE762163 & LUZU001234 & $\mathrm{NHC}$ & 2 & 2 & $n / a$ & 1 & 2019-02-21 09:37:50 & Duplicate - Multiple Teams & & $\mathbf{A}$ & $v$ & $\square$ \\
\hline KJTU34561 & LUZU001252 & $\mathrm{NHC}$ & 3 & 3 & $\mathrm{n} / \mathrm{a}$ & 1 & $2019-02-2109: 36: 32$ & Duplicate - Within Team & & $\mathbf{A}$ & $\checkmark$ & $\square$ \\
\hline RHJK73924 & LUZU001222 & $\mathrm{NHC}$ & 4 & 6 & $n / a$ & 1 & 2019-02-2109:35:34 & Added to List & 目 & $\boldsymbol{A}$ & 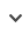 & $\square$ \\
\hline WNTA74839 & LUZU001215 & $\mathrm{NHC}$ & 5 & 10 & $n / a$ & 2 & & Not Observed & & $\boldsymbol{A}$ & $\checkmark$ & $\square$ \\
\hline
\end{tabular}

Inventory Lead Comments

- Resolve after merging observation(s) with

items and adding a comment

Add a comment.

- Acknowledge an item after adding a comment.

- Cancel to exit with no action.

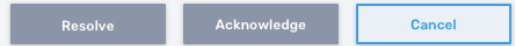

Figure 29. Reconciliation page for item WNTA762169 (Not Observed) after inventory lead selects item WNTA762196 (Added to List) to merge. 
The Resolve and Acknowledge buttons remained disabled until the inventory lead adds a comment describing the situation at which point the Resolve is enabled (Figure 30).

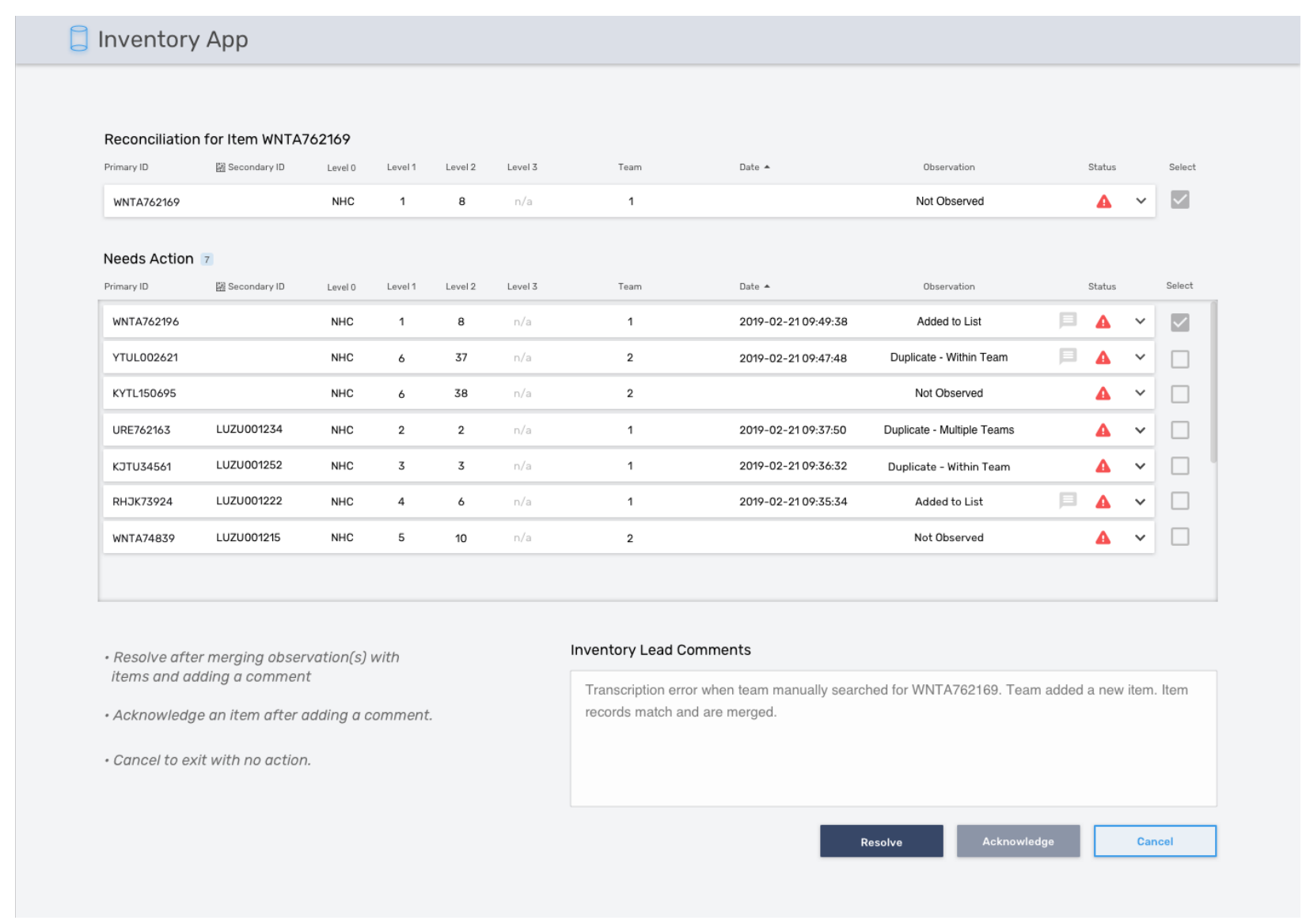

Figure 30. Reconciliation page for item WNTA762169 (Not Observed) after inventory lead adds a comment. 
The inventory lead selects Resolve to merge the two items, which navigates the lead back to the main integration page. On the main page, the two items are removed from the Needs Action category, and the merged item (WNTA762169) is moved to the Completed category. The merged item's composite observation is changed to Observed and the reconciliation status is grayed out (Figure 31). Furthermore, the merged items are removed from the Needs Action section on subsequent reconciliation pages.

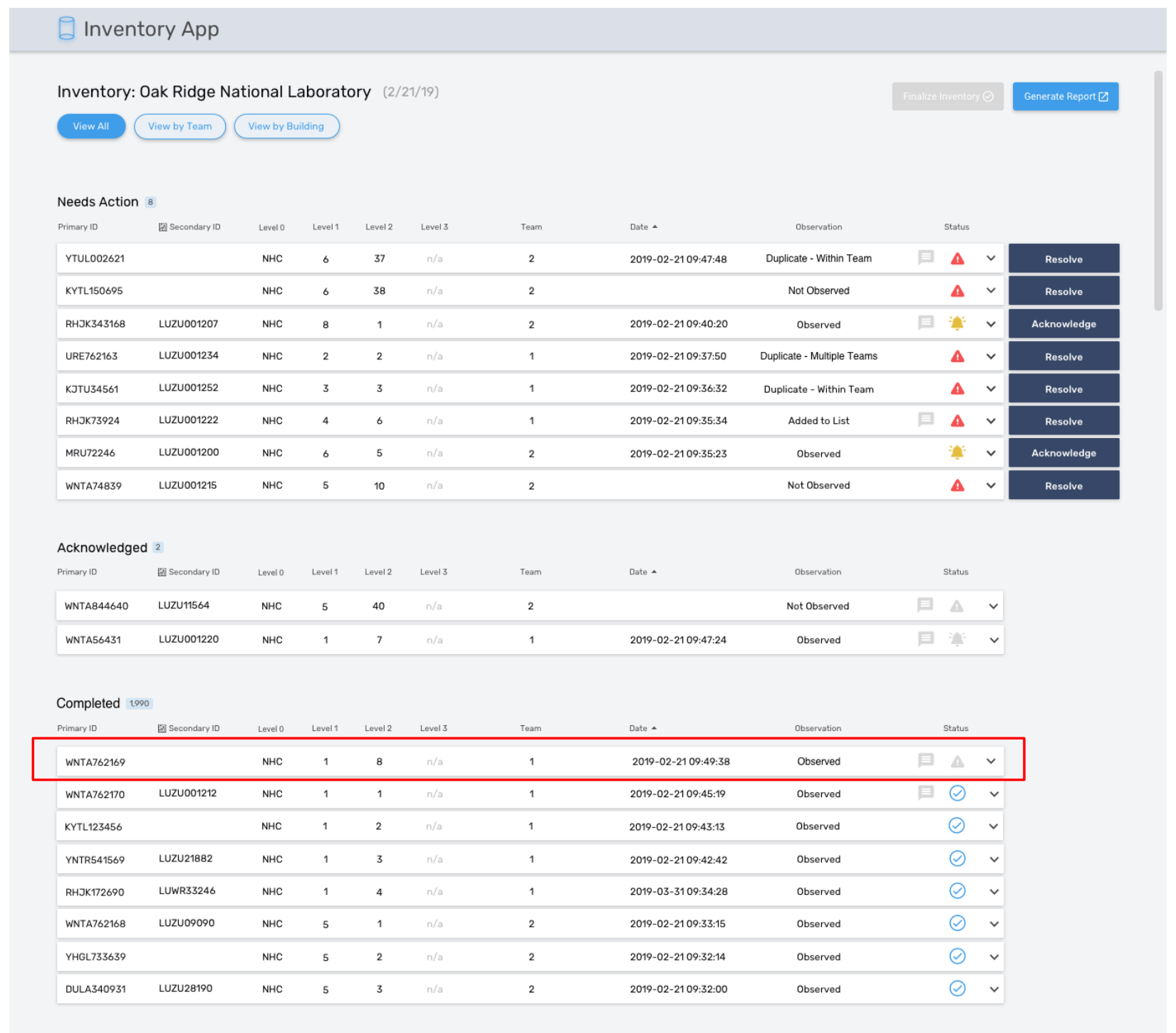

Figure 31. Merged item WNTA762169 after the inventory lead resolves the error. 


\subsection{RESOLVE AN ERROR-ASSOCIATE AN OBSERVATION TO CORRECT ITEM}

We expect teams may accidentally record an observation to the wrong item, as described in scenario 11 in Table 4 in Table 8 . This section walks through a concrete example of how the inventory lead could correct such an error. For example, items KYTL15095 and YTUL002621 are physically located next to each other in the facility so their identification numbers are next to each other on the IFOA. Team A sees item KYTL15095 but accidentally recorded an observation to item YTUL002621 (e.g., swiped right on YTUL002621 and does not notice). Team A then sees YTUL002621, but YTUL002621 shows up as Observed on the IFOA. This means Team A would need to record the observation for YTUL002621 as a duplicate. After integration on DIRA, item YTUL002621 has a composite observation of "Duplicate Within Team," and item KYTL15095 is Not Observed (Figure 32).

Both items have an error status icon and an enabled Resolve button to the right of the item's row. The inventory lead selects the Resolve button for item YTUL002621 to navigate to a separate reconciliation page (Figure 33).

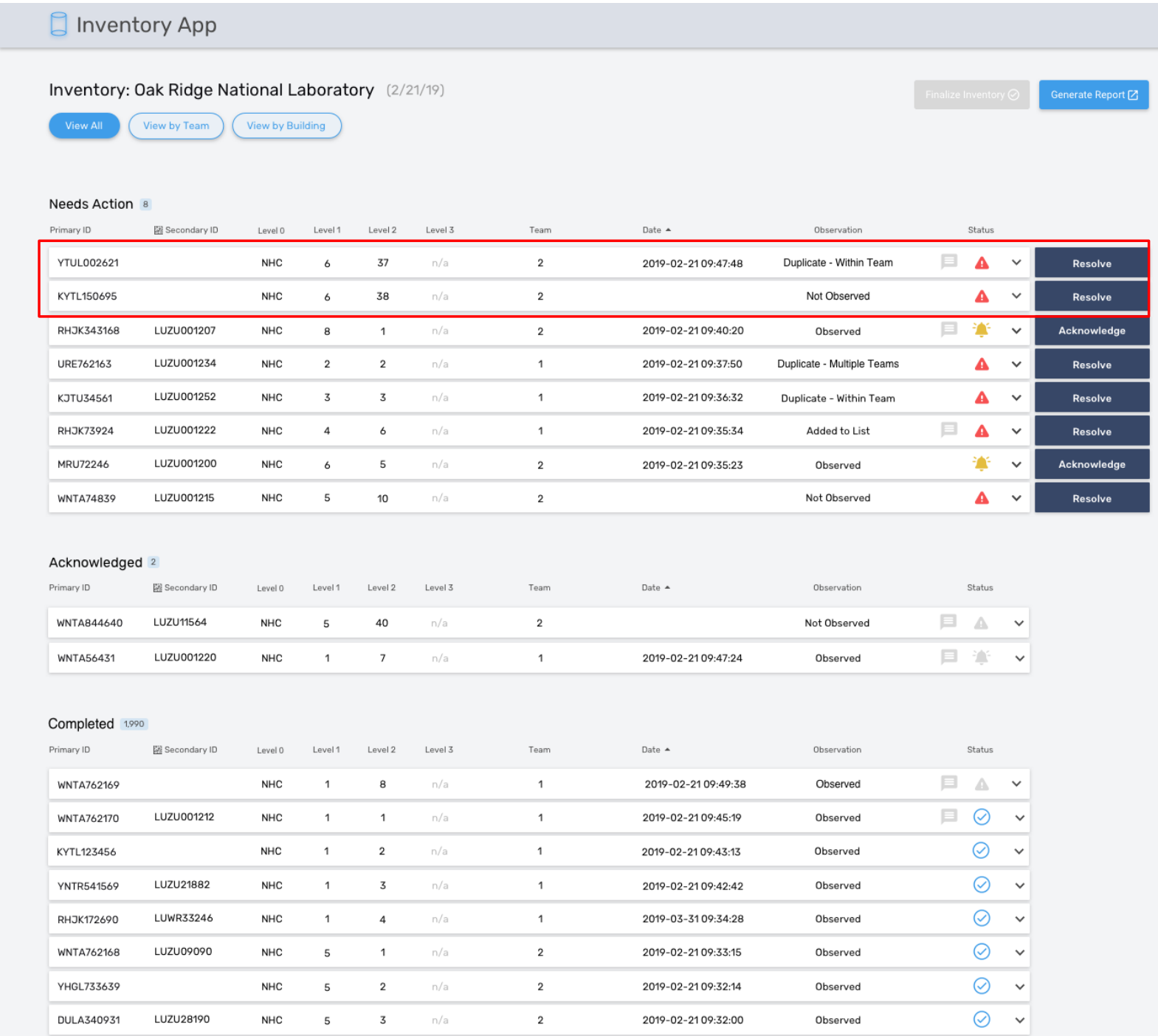

Figure 32. Items YTUL002621 (Duplicate - Within Team) and KYTL15095 (Not Observed) have an error reconciliation status and need action by the inventory lead. 


\begin{tabular}{|c|c|c|c|c|c|c|c|c|c|c|c|c|}
\hline Primary ID & Tit Secondary 10 & Level 0 & Level1 & Level 2 & Level 3 & Team & Date . & observation & \multicolumn{3}{|c|}{ Status } & Select \\
\hline \multirow[t]{3}{*}{ YTUL002621 } & & $\mathrm{NHC}$ & 6 & 37 & $\mathrm{n} / \mathrm{a}$ & 2 & $2019-02-2109: 47: 48$ & Duplicate - Within Team & 曰 & $\mathbf{A}$ & $\checkmark$ & $\checkmark$ \\
\hline & & & & & & & 2019-02-2109:47:48 & Duplicate - Within Team & 目 & & & $\checkmark$ \\
\hline & & & & & & & $2019-02-2109: 46: 23$ & Observed & & & & $\checkmark$ \\
\hline
\end{tabular}

Needs Action 5

\begin{tabular}{|c|c|c|c|c|c|c|c|c|c|c|c|c|}
\hline Primary ID & Secondary 10 & Level 0 & Level1 & Level 2 & Level 3 & Team & Date - & Observation & & Status & & Select \\
\hline KYTL150695 & & $\mathrm{NHC}$ & 6 & 38 & n/a & 2 & & Not Observed & & $\boldsymbol{A}$ & 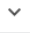 & $\square$ \\
\hline URE762163 & LUZU001234 & $\mathrm{NHC}$ & 2 & 2 & $\mathrm{n} / \mathrm{a}$ & 1 & $2019-02-2109: 37: 50$ & Duplicate - Multiple Teams & & $\mathbf{A}$ & 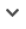 & $\square$ \\
\hline KJTU34561 & LUZU001252 & $\mathrm{NHC}$ & 3 & 3 & $n / a$ & 1 & $2019-02-2109: 36: 32$ & Duplicate - Within Team & & $\mathbf{A}$ & 2 & $\square$ \\
\hline RHJK73924 & LUZU001222 & $\mathrm{NHC}$ & 4 & 6 & $n / a$ & 1 & 2019-02-21 09:35:34 & Added to List & 目 & $\mathbf{A}$ & 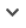 & $\square$ \\
\hline WNTA74839 & LUZU001215 & $\mathrm{NHC}$ & 5 & 10 & $n / a$ & 2 & & Not Observed & & $\mathbf{A}$ & 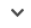 & $\square$ \\
\hline
\end{tabular}

- Resolve after merging observation(s) with items and adding a comment

Inventory Lead Comments

- Acknowledge an item after adding a comment.

Add a comment.

- Cancel to exit with no action.

Figure 33. Initial reconciliation page for item YTUL002621 (Duplicate - Within Team). 
In this hypothetical example, the inventory lead speaks with the operator who says the item is present onsite based on the facility records. The inventory lead begins to browse the Needs Action section by sorting items based on the composite observation. The inventory lead notes that item KYTL150695 has a Not Observed composite observation and was added to the inventory list by the same team assigned to item YTUL002621. Additionally, the lead notes that the two items are located next to each other in the facility.

By looking at the information for both items, speaking with the operator, and speaking with the inventory team, the lead determines the inventory team accidentally swiped right on YTUL002621 when observing neighboring item KYTL150695. When the inventory team got to item YTUL002621 in the field and tried to record an observation, the team had to manually add it as duplicate on their IFOA. To resolve, the inventory lead deselects the oldest observation under item YTUL002621 and selects the checkbox next to item KYTL150695 (Figure 34).

Inventory App

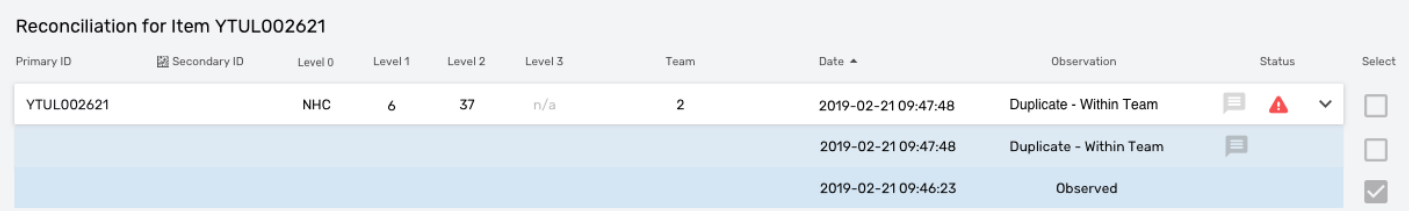

\begin{tabular}{|c|c|c|c|c|c|c|c|c|c|c|c|}
\hline Primary ID & : 2 Secondary 10 & Level 0 & Level1 & Level2 & Level 3 & Team & Date - & observation & & Status & \\
\hline KYTL150695 & & $\mathrm{NHC}$ & 6 & 38 & $n / a$ & 2 & & Not Observed & & $\mathbf{A}$ & $v$ \\
\hline URE762163 & LUZU001234 & $\mathrm{NHC}$ & 2 & 2 & $n / a$ & 1 & $2019-02-2109: 37: 50$ & Duplicate - Multiple Teams & & $\mathbf{A}$ & 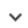 \\
\hline KJTU34561 & LUZU001252 & $\mathrm{NHC}$ & 3 & 3 & $n / a$ & 1 & $2019-02-2109: 36: 32$ & Duplicate - Within Team & & $\mathbf{A}$ & v \\
\hline RHJK73924 & LUZU001222 & $\mathrm{NHC}$ & 4 & 6 & $n / a$ & 1 & $2019-02-2109: 35: 34$ & Added to List & 目 & $\mathbf{A}$ & 2 \\
\hline WNTA74839 & LUZU001215 & $\mathrm{NHC}$ & 5 & 10 & n/a & 2 & & Not Observed & & $\mathbf{A}$ & 2 \\
\hline
\end{tabular}

Resolve after merging observation(s) with

items and adding a comment

Inventory Lead Comments

- Acknowledge an item after adding a comment.

Add a comment.

- Cancel to exit with no action.

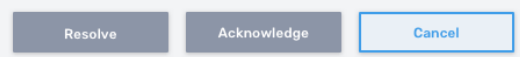

Figure 34. Reconciliation page for item YTUL002621 (Duplicate - Within Team) after inventory lead selects item KYTL150695 (Not Observed) to merge. 
After adding a comment that describes the situation (Figure 35), the Resolve button is enabled at the bottom of the page.

$$
\text { I Inventory App }
$$

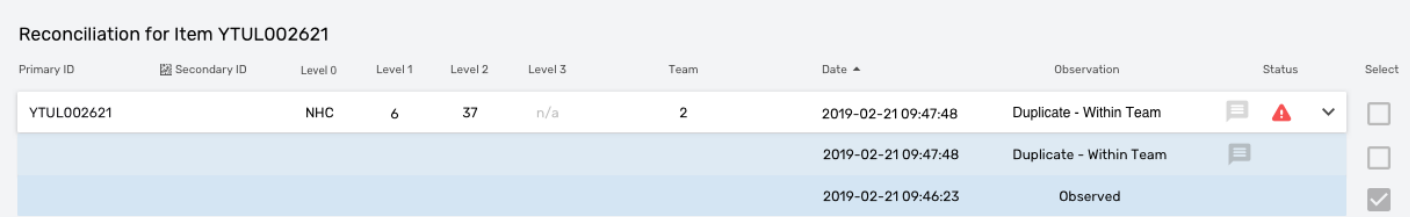

\begin{tabular}{|c|c|c|c|c|c|c|c|c|c|c|c|c|}
\hline Primary ID & 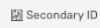 & Level 0 & Level1 & Level 2 & Level 3 & Team & Date - & observation & & Status & & Select \\
\hline KYTL150695 & & $\mathrm{NHC}$ & 6 & 38 & $n / a$ & 2 & & Not Observed & & $\mathbf{A}$ & $v$ & $\checkmark$ \\
\hline URE762163 & LUZU001234 & NHC & 2 & 2 & $\mathrm{n} / \mathrm{a}$ & 1 & $2019-02-2109: 37: 50$ & Duplicate - Multiple Teams & & $\mathbf{A}$ & $\checkmark$ & $\square$ \\
\hline KJTU34561 & LUZU001252 & NHC & 3 & 3 & $n / a$ & 1 & $2019-02-2109: 36: 32$ & Duplicate - Within Team & & $\mathbf{A}$ & $v$ & $\square$ \\
\hline RHJK73924 & LUZU001222 & NHC & 4 & 6 & $n / a$ & 1 & $2019-02-2109: 35: 34$ & Added to List & 国 & $\mathbf{A}$ & $\checkmark$ & $\square$ \\
\hline WNTA74839 & LUZU001215 & NHC & 5 & 10 & $\mathrm{n} / \mathrm{a}$ & 2 & & Not Observed & & $\mathbf{A}$ & $v$ & $\square$ \\
\hline
\end{tabular}

Resolve after merging observation(s) with items and adding a comment

- Acknowledge an item after adding a comment.

- Cancel to exit with no action.
Inventory Lead Comments

Team accidentally swiped right on YTUL002621 when observing KYTL150695. Then, team observed YTUL002621 in the field and added it as a duplicate.

Figure 35. Reconciliation page for item YTUL002621 (Duplicate - Within Team) after inventory lead adds a comment. 
The inventory lead then selects the Resolve button to merge the oldest observation under the YTUL002621 with item KYTL150695. On the main page, YTUL002621 and KYTL150695 are removed from the Needs Action category and are moved to the Completed category. For the merged item KYTL150695 and the remaining observation for YTUL002621, the composite observations are changed to Observed and the reconciliation statuses are grayed out (Figure 36). Furthermore, both items are removed from the Needs Action section on subsequent reconciliation pages.

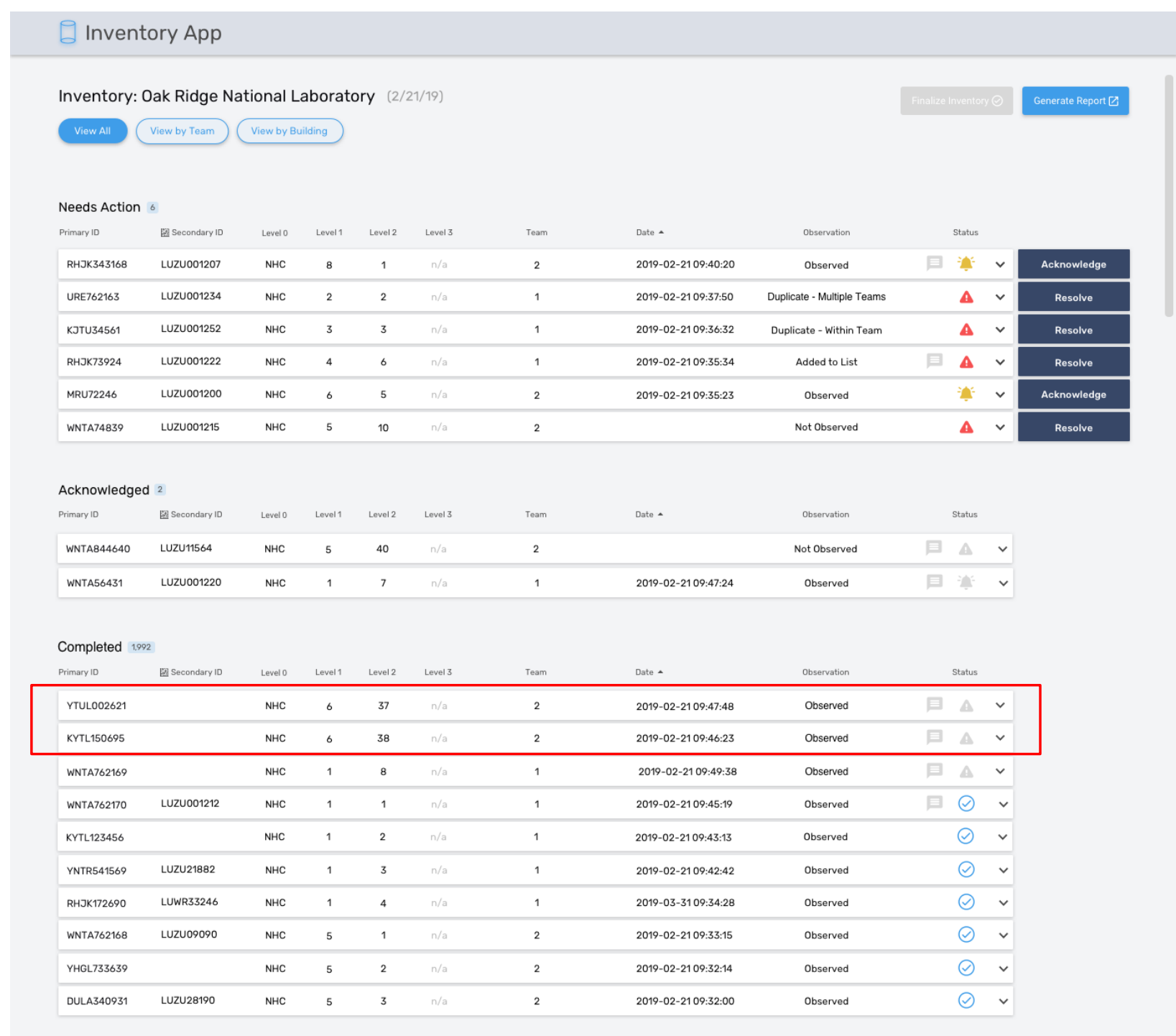

Figure 36. Items YTUL002621 and KYTL150695 after the inventory lead resolves the errors.

\subsection{GENERATE SUMMARY REPORT AND FINALIZE INVENTORY}

The inventory lead may generate a summary report at any point during the integration and reconciliation process by clicking the "Generate Report" button (Figure 37). The report is not shown here, but is expected to mirror the layout of the integrated observations logs showing the items in the Needs Action, Acknowledged, and Completed categories as follows:

- Needs Action: Presents information for all items that still require action by the inventory lead. This includes displaying all observations of an item and any comments made by the inventory team in the 
field. If the summary report is generated at the end of the inventory activity, this category will be empty.

- Acknowledged: Presents each acknowledged item as one row with the inventory lead's comment from the reconciliation process printed below.

- Completed: For items that were added to this category through the reconciliation process, this section presents each resolved item as one row with the inventory lead's comment printed below. For items that were placed in the completed category after the initial integration, this section presents each item as one row. If any comments were added by the inventory teams, these comments are printed below the item.

The summary report may be printed at any time to distribute to the inventory teams or operators, which may be helpful to the inventory lead during the reconciliation process.

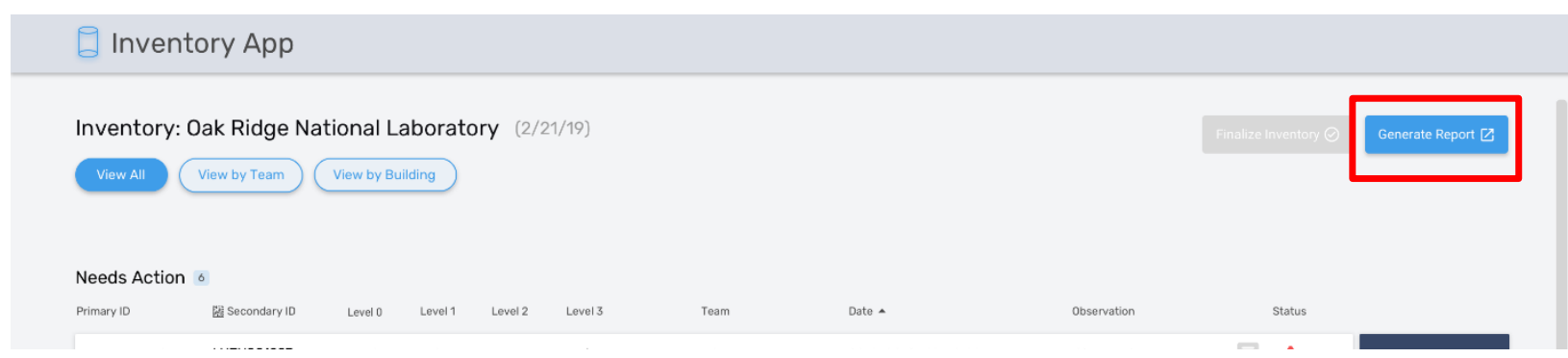

Figure 37. Generate summary report.

When there are no items in the Needs Action category and the inventory lead is satisfied with the reconciliation activities, they may finalize the inventory by selecting the "Finalize" button (Figure 38). This prompts the pop-up shown in Figure 39 which the inventory lead must confirm before progressing. After the report is finalized, the inventory lead or operators may not go back to perform reconciliation activities. However, they are still able to look at the integrated observations logs and produce a summary report if desired.

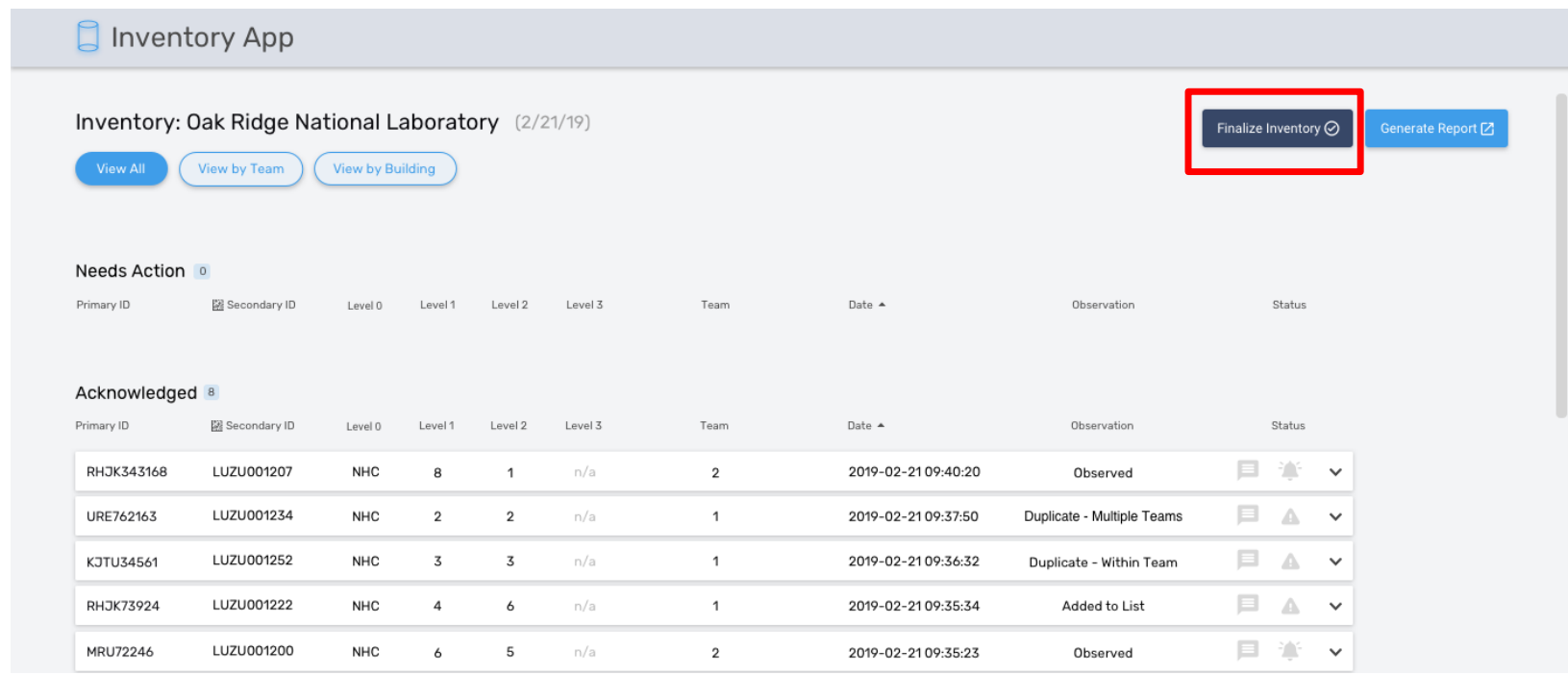

Figure 38. Finalize inventory. 


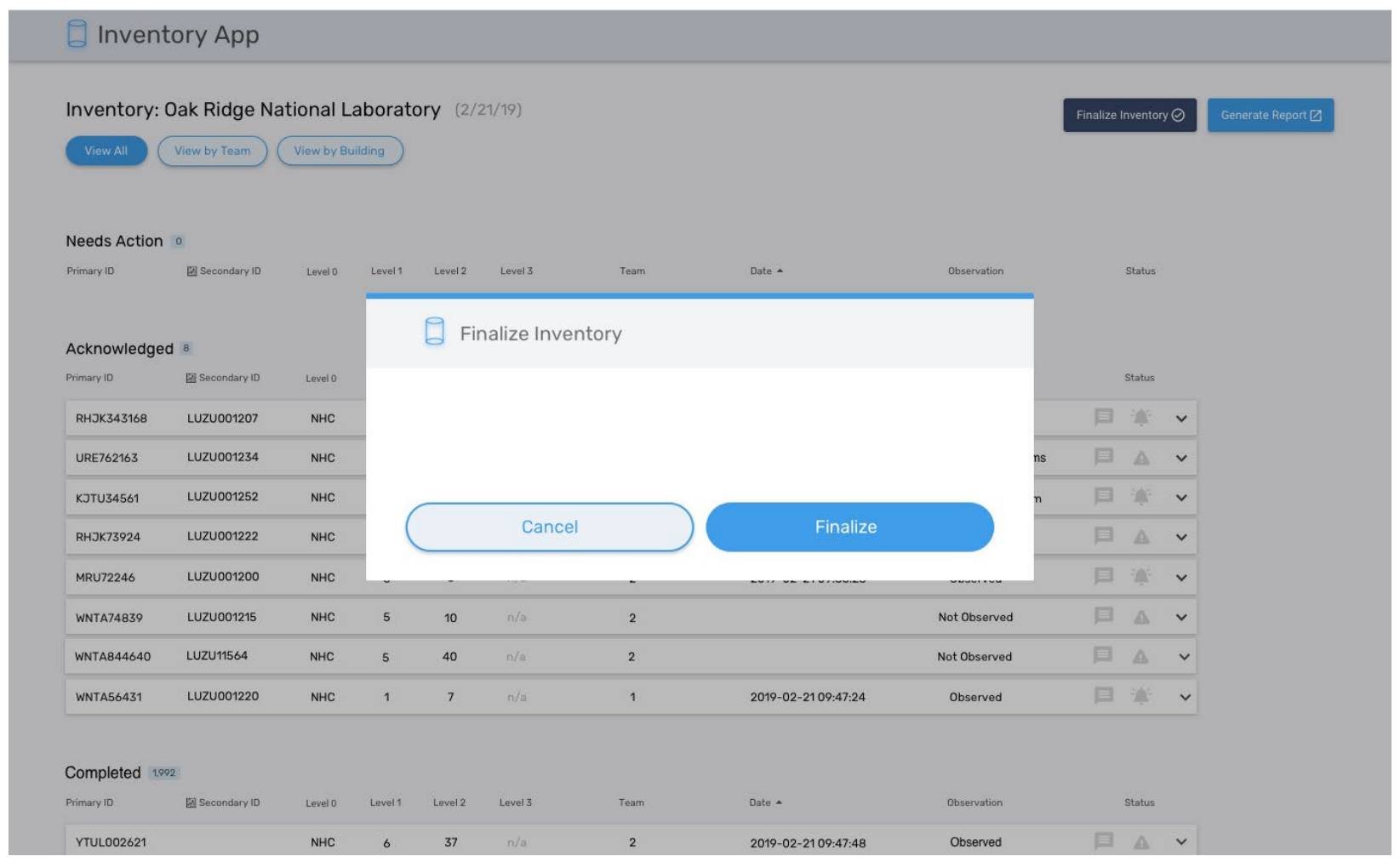

Figure 39. Finalize inventory pop-up message.

\section{SUMMARY AND FUTURE WORK}

This paper reviewed the conceptual workflow, described more fully the process to reconcile conflicting observations, and demonstrated the user experience for the Distribution, Integration, and Reconciliation Application. This document was intended to provide the reader an overview of the conceptual workflow and user experience as a step on our path towards development. The screens presented in this report are non-functional prototypes developed primarily using the Sketch software. These prototype screens helped the authors solidify the conceptual approach and consider the complexities of reconciling conflicting observations. The authors have engaged with several development teams and are poised to develop the software when funded to do so.

\section{REFERENCES}

1. Garner, J., McGirl, N.A., and Whitaker, J.M., A Conceptual Design for a Mobile Application to Support Infield Inventory Activities, Report no. ORNL/TM-2020/1646, Oak Ridge National Laboratory, Oak Ridge, TN, October 2020.

2. World Nuclear Transport Institute Standard, $\mathrm{UF}_{6}$ Cylinder Identification, Version 1, 2017.

3. White-Horton, J., et al., The Life Cycle of 30B and 48Y Cylinders, Report no. ORNL/TM-2011/522, Oak Ridge National Laboratory, Oak Ridge, TN, April 2012.

4. Cooley, J., et al., Opportunities for the IAEA to use a $\mathrm{UF}_{6}$ Global Identifier for Safeguards, Report no. ORNL/TM-2017/283, Oak Ridge National Laboratory, Oak Ridge, TN, June 2017.

5. International Atomic Energy Agency. IAEA Safeguards Glossary, 2001 Edition, International Nuclear Verification Series No. 3, Vienna, 2002. 
